Old Dominion University

ODU Digital Commons

$9-2015$

Global Projections of Intense Tropical Cyclone Activity for the Late Twenty-First Century from Dynamical Downscaling of CMIP5/RCP4.5 Scenarios

Thomas R. Knutson

Joseph J. Sirutis

Ming Zhao

Robert E. Tuleya

Morris Bender

See next page for additional authors

Follow this and additional works at: https://digitalcommons.odu.edu/ccpo_pubs

Part of the Atmospheric Sciences Commons, Climate Commons, and the Meteorology Commons 


\section{Authors}

Thomas R. Knutson, Joseph J. Sirutis, Ming Zhao, Robert E. Tuleya, Morris Bender, Gabriel A. Vecchi, Gabriele Villarini, and Daniel Chavas 


\title{
Global Projections of Intense Tropical Cyclone Activity for the Late Twenty-First Century from Dynamical Downscaling of CMIP5/RCP4.5 Scenarios
}

\author{
Thomas R. Knutson, Joseph J. Sirutis, And Ming ZhaO \\ NOAA/Geophysical Fluid Dynamics Laboratory, Princeton, New Jersey \\ ROBERT E. TULEYA \\ Center for Coastal Physical Oceanography, Old Dominion University, Norfolk, Virginia \\ MorRis Bender AND GABRIEL A. VECCHI \\ NOAA/Geophysical Fluid Dynamics Laboratory, Princeton, New Jersey \\ GABRIELE VILLARINI \\ IIHR-Hydroscience and Engineering, The University of Iowa, Iowa City, Iowa \\ DANIEL CHAVAS \\ Department of Civil and Environmental Engineering, Princeton University, \\ Princeton, New Jersey
}

(Manuscript received 11 February 2015, in final form 30 June 2015)

\begin{abstract}
Global projections of intense tropical cyclone activity are derived from the Geophysical Fluid Dynamics Laboratory (GFDL) High Resolution Atmospheric Model (HiRAM; 50-km grid) and the GFDL hurricane model using a two-stage downscaling procedure. First, tropical cyclone genesis is simulated globally using HiRAM. Each storm is then downscaled into the GFDL hurricane model, with horizontal grid spacing near the storm of $6 \mathrm{~km}$, including ocean coupling (e.g., "cold wake" generation). Simulations are performed using observed sea surface temperatures (SSTs) (1980-2008) for a "control run" with 20 repeating seasonal cycles and for a late-twenty-first-century projection using an altered SST seasonal cycle obtained from a phase 5 of CMIP (CMIP5)/representative concentration pathway 4.5 (RCP4.5) multimodel ensemble. In general agreement with most previous studies, projections with this framework indicate fewer tropical cyclones globally in a warmer late-twenty-first-century climate, but also an increase in average cyclone intensity, precipitation rates, and the number and occurrence days of very intense category 4 and 5 storms. While these changes are apparent in the globally averaged tropical cyclone statistics, they are not necessarily present in each individual basin. The interbasin variation of changes in most of the tropical cyclone metrics examined is directly correlated to the variation in magnitude of SST increases between the basins. Finally, the framework is shown to be capable of reproducing both the observed global distribution of outer storm size-albeit with a slight high bias_and its interbasin variability. Projected median size is found to remain nearly constant globally, with increases in most basins offset by decreases in the northwest Pacific.
\end{abstract}

Corresponding author address: Thomas R. Knutson, NOAA/Geophysical Fluid Dynamics Laboratory, Climate Impacts and Extremes Group, 201 Forrestal Road, Princeton, NJ 08542.

E-mail: tom.knutson@noaa.gov

DOI: 10.1175/JCLI-D-15-0129.1 


\section{Introduction}

The question of how tropical cyclone ${ }^{1}$ activity could be altered by future anthropogenic warming (Knutson et al. 2010; Christensen et al. 2013) is complicated by a number of factors. First, past observational data are of limited use for enhancing confidence in future projections because it remains uncertain whether past changes in any tropical cyclone metric exceed the level expected from natural processes alone (Knutson et al. 2010). One exception to this assessment discussed by IPCC (2013) concerns the likely role of anthropogenic aerosol forcing (along with natural variability) in contributing to a temporary decrease in Atlantic hurricane activity during the 1970s and 1980s (e.g., Villarini and Vecchi 2012, 2013; Dunstone et al. 2013). A second issue is that uncertainties in the patterns of future sea surface temperature (SST) changes can lead also to uncertainties in the associated tropical cyclone projections (Zhao et al. 2009; Sugi et al. 2009; Knutson et al. 2013). There is also an important dependence of tropical cyclone intensity on the vertical structure of atmospheric temperature changes, for which at least some historical data/reanalyses are likely to have important shortcomings (Vecchi et al. 2013). Finally, numerous studies have found that the relatively coarse grid global models, such as those used in phase 3 of the Coupled Model Intercomparison Project (CMIP3; Meehl et al. 2007) or phase 5 (CMIP5; Taylor et al. 2012) usually do not produce very realistic climatological tropical cyclone activity (Camargo et al. 2013) and are particularly deficient at simulating very intense (category 4 and 5) tropical cyclones. Our previous studies of tropical cyclones for the Atlantic basin (Bender et al. 2010; Knutson et al. 2013) found that the simulated frequency response of very intense tropical cyclones to climate warming differs from that of weaker tropical cyclones: the intense tropical cyclones tend to increase in frequency whereas the weaker tropical cyclones tend to decrease in frequency in these simulations, using a variety of CMIP3 and CMIP5 model scenarios as boundary forcings. Thus, some form of downscaling, for example by regional or global model time-slice experiments (Murakami et al. 2012b; Knutson et al. 2013), statistical downscaling (Zhao and Held 2010), or statistical/ deterministic downscaling (Emanuel et al. 2008; Emanuel 2013), has commonly been used to attempt to gain insight into the response of tropical cyclone activity to

\footnotetext{
${ }^{1}$ We use the term "tropical cyclone" in this report to refer collectively to tropical storms and hurricanes (i.e., to tropical cyclones with intensities exceeding $17.5 \mathrm{~m} \mathrm{~s}^{-1}$ ), with the latter having intensities greater than $33 \mathrm{~m} \mathrm{~s}^{-1}$ regardless of their basin of occurrence.
}

climate change despite the coarse-resolution limitations of the CMIP3 and CMIP5 climate models.

In this study, the main focus will be on using a dynamical downscaling approach to investigate the response of tropical cyclones in all basins to a climate change scenario obtained from a multimodel ensemble of CMIP5 models (RCP4.5 scenario). Our approach closely follows that of Bender et al. (2010) and Knutson et al. (2013) for the Atlantic basin, but extends this approach to all ocean basins, with some methodological adjustments as discussed in the model description section. Among other published studies of possible future global tropical cyclone activity, that of Murakami et al. (2012b) appears exceptional in terms of the dynamical model's capability of simulating very intense (category 4 and 5) tropical cyclones. However, even in that case, the model used by Murakami et al. did not include ocean coupling, in which a storm generates a "cold wake" in the SST field, particularly when traveling over regions with a relatively shallow mixed layer. This process can be an important negative feedback on tropical cyclone intensity (e.g., Bender and Ginis 2000; Lin et al. 2013), which could possibly alter the tropical cyclone response to climate change [although see Knutson et al. (2001) for an early assessment of this mechanism showing little effect]. Therefore the present study appears to be unique in comparison to previously published tropical cyclone global projection studies in that the models can simulate very intense (category 4 and 5) storms in various basins using relatively high spatial resolution near the storm (as fine as $6 \mathrm{~km}$ ) while including ocean coupling as a negative feedback on intensity.

As a preliminary test of the downscaling approach, we first simulate global tropical cyclone activity for the years 1980-2008 using observed interannually varying SST and sea ice distributions. Each of these 3081 simulated tropical cyclones (compared to 2518 tropical cyclones for the same period in observations) is then downscaled into the Geophysical Fluid Dynamics Laboratory (GFDL) hurricane model so that higherintensity storms (category 4 and 5) can be simulated and compared with observations in each basin. For observed storm tracks and intensity, we use the HURDAT and Joint Typhoon Warning Centers (JTWC) tropical cyclone datasets, except as noted in the text. We then simulate and compare present-day and late-twenty-firstcentury climate conditions using two sets of 20 -yr runs based on a repeating seasonal cycle design (no interannual variability) as described in section 2 . Thus, in summary, we perform three basic sets of experiments: historical (with interannually varying SSTs), presentday control (repeating seasonal cycle), and late-twentyfirst century (repeating seasonal cycle). 
TABLE 1. Summary of the 13 CMIP5 (Taylor et al. 2012) global climate models used in this study to create the multimodel anomalies in HiRAM (using SST and sea ice concentration). (Expansions of acronyms are available online at http://www.ametsoc.org/PubsAcronymList.)

\begin{tabular}{lc}
\hline \hline & Modeling center (or group) \\
\hline Canadian Centre for Climate Modeling and Analysis & CanESM2 \\
Centre National de Recherches Meteorologiques/Centre Europeen de Recherche et Formation Avancees en & CNRM-CM5 \\
Calcul Scientifique & CSIRO-Mk3.6.0 \\
Commonwealth Scientific and Industrial Research Organization in collaboration with Queensland Climate & \\
Change Centre of Excellence & FGOALS-g2 \\
Chinese Academy of Sciences, State Key Laboratory Numerical Modeling for Atmospheric Sciences and & GFDL-CM3 \\
Geophysical Fluid Dynamics & GFDL-ESM2G \\
NOAA Geophysical Fluid Dynamics Laboratory & GFDL-ESM2M \\
NOAA Geophysical Fluid Dynamics Laboratory & HadGEM2-ES \\
NOAA Geophysical Fluid Dynamics Laboratory & MIROC5 \\
Met Office Hadley Centre & MIROC-ESM \\
Atmosphere and Ocean Research Institute (The University of Tokyo), National Institute for Environmental & \\
Studies, and Japan Agency for Marine-Earth Science and Technology & \\
Japan Agency for Marine-Earth Science and Technology, Atmosphere and Ocean Research Institute (The & MPI-ESM-LR \\
University of Tokyo), and National Institute for Environmental Studies & MRI-CGCM3 \\
Max Planck Institute for Meteorology & NorESM1-M \\
Meteorological Research Institute & \\
Norwegian Climate Centre &
\end{tabular}

\section{Model description}

We use a two-step downscaling procedure to simulate tropical cyclones in our study. First we use a global atmospheric model (50-km grid spacing) forced by a present-day or future climate SSTs, sea ice, and appropriate greenhouse gas levels to obtain a distribution of tropical cyclone genesis. Each tropical cyclone generated using this global model is then downscaled into the GFDL hurricane model, which is a regional model that uses multiple layers of nesting to focus resolution on a single tropical cyclone (grid spacing as fine as $6 \mathrm{~km}$ ) for the duration of the cyclone, beginning from the time the cyclone first reaches tropical storm intensity in the global model.

\section{a. HiRAM C180 global model}

The GFDL High Resolution Atmospheric Model (HiRAM C180; 50-km grid) used to simulate the genesis of tropical cyclones is described in Zhao et al. (2009). Given the global SST distribution and evolution, this model has a demonstrated ability to simulate the interannual variability of tropical cyclone occurrence quite realistically, especially in the Atlantic basin, but also to a reasonable degree in the northeast and northwest Pacific basins (Zhao et al. 2009).

To reduce the confounding influence of interannual variability ("noise") on our climate change sensitivity runs, we run control (present day) and late-twenty-firstcentury downscaling experiments using 20 repeating identical seasonal cycles of SST and external forcings for each climate regime, with the control seasonal cycle based on the time average (1982-2005) of the HadISST SST dataset (see Zhao et al. 2009). Thus we are not attempting to model the effect of any climate changeinduced changes in interannual variability (e.g., El Niño-Southern Oscillation) in our cyclone simulations. For the late-twenty-first-century climate change runs, the changes in SSTs, sea ice, and greenhouse gas concentrations from the control run conditions are based on the difference between 20-yr mean climatologies from the multimodel mean of the CMIP5 RCP4.5 scenario for years 2081-2100 (i.e., late twenty-first century) and years 2001-20 (i.e., present day). Note there is a 15 -yr difference between the midpoint year of our control condition SSTs (1994) and the midpoint year of the baseline "present-day" period for the RCP4.5 climate change calculations (2010). Therefore if one assumes the control case to be representative of conditions for 1994, rather than 2010, then the so-called late-twentyfirst-century scenarios would correspond approximately to the 20-yr period centered on 2075 (rather than 2090) as obtained from the CMIP5/RCP4.5 scenarios. For these climate change perturbation experiments the SST increase in the various tropical storm basins ranges from $1.1^{\circ}$ to $1.7^{\circ} \mathrm{C}$ as discussed in more detail later in this report.

The 13 CMIP5 climate models (RCP4.5 scenario) that are used in our study are listed in Table 1. Our selection of these 13 models was based on the availability of sea ice concentration data at the time our multimodel ensemble was constructed for our earlier study (Knutson et al. 2013), and we have continued to use the same models in the present study. 


\section{b. GFDL hurricane model}

The individual tropical cyclones detected in the HiRAM C180 global model [see Zhao et al. (2009) for details of the detection scheme] are rerun at enhanced resolution, and with ocean coupling, using a version of the operational GFDL hurricane model. The hurricane model consists of a triply nested moveable mesh atmospheric model coupled to the Princeton Ocean Model (POM; Bender et al. 2007). The $5^{\circ}$ latitude by $5^{\circ}$ longitude inner nest of the regional atmospheric model has, in the version used in the present study, a horizontal grid spacing of about $6 \mathrm{~km}$ (i.e., $1 / 18^{\circ}$ ). The middle nest covers an $11^{\circ} \times 11^{\circ}$ region with a grid spacing of $16^{\circ}$. The high-resolution (inner and middle) nests move along with the storm to maintain enhanced resolution in the vicinity of the tropical cyclone. The stationary outer domain spans $115^{\circ}$ in the east-west direction and $50^{\circ}$ in the north-south direction with a grid spacing of $1 / 2^{\circ}$ and is positioned for each tropical storm basin. The atmospheric model physics has been modified from that used in Bender et al. (2010) and Knutson et al. (2013) by implementing the physics upgrades in the GFDL operational hurricane model adopted in 2012 (including upgrades in cloud microphysics, cumulus parameterizations, and boundary layer and surface physics). (See http://www.nws.noaa.gov/os/notification/tin12-18gfdl_ aaa.htm for more details). The only exception is that the inner-nest resolution in our experiments is set as $1 / 18^{\circ}$ $(\sim 6 \mathrm{~km})$ and the criterion for large-scale condensation was appropriately modified. The hurricane model experiments were run for up to 15 days, which allowed the entire tropical cyclone lifetime of almost all storms to be simulated, including the landfalling stages.

The ocean coupling included in our experiments provides an important physical process for the simulations, allowing the tropical cyclone to influence the ocean and generating a cold wake in the SSTs, which can in turn affect the cyclone's intensity. As in the operational prediction version of the model, the GFDL hurricane model's atmospheric component was coupled to a one-dimensional version of the POM model for all basins except the North Atlantic, where a threedimensional version was used. The ocean model was initialized by the atmospheric analysis SST at the surface and observed [U.S. Navy Generalized Digital Environmental Data (GDEM)] climatology below, using an assimilation methodology that prevents convective instability in any model layers (Yablonsky and Ginis 2008). The integrations were initiated at the first diagnosed time of tropical storm intensity for the HiRAM global model and initialized by interpolation without any synthetic vortex replacement (or bogusing), such that the peak wind speed and radius of maximum wind in GFDL hurricane model at the initial time is the same as that found in HiRAM. It is possible that some incipient disturbances that failed to develop in the HiRAM simulation would have developed into at least tropical storms had they been initialized as weak disturbances in the GFDL hurricane model. Thus we are relying on the HiRAM solution to define the number of tropical cyclone cases to downscale. For the climate change experiments, we assumed that the ocean mixed layer depth (defined here as the maximum depth at which the ocean temperature is no more than $0.5^{\circ} \mathrm{C}$ lower than at the surface) was unchanged in the warmer climate. That is, the SST change from the climate models was applied through the entire mixed layer. Below the mixed layer, this warming perturbation was tapered to zero, with the tapering adjusted so that the vertical temperature gradient did not exceed $0.04^{\circ} \mathrm{C} \mathrm{m}^{-1}$ (following Yablonsky and Ginis 2008). A recent study Huang et al. (2015) suggests that including the enhanced vertical gradient of upper ocean surface temperature from CMIP5 late-twenty-firstcentury simulations can reduce substantially the intensification of TCs with climate change relative to a case with no change in vertical gradient. While our experiments include an enhanced vertical gradient beneath the mixed layer, a more detailed comparison with the findings of Huang et al. is a subject of a future study. Note that the cold wakes generated by the storms are only affecting the high-resolution nested experiments. The storms do not feed back onto SSTs in HiRAM. The original climate models would have included some impact of simulated tropical cyclones on the ocean, although those storms were much less intense and distributed differently in time than those in the dynamical downscaling framework analyzed here; thus, we expect any impact of this effect on our results to be small.

\section{Simulated versus observed tropical cyclone activity}

In this section, we compare simulated and observed tropical cyclone activity in terms of annual counts, tracks, intensity distribution, precipitation distribution, and storm size. Tropical cyclone activity as simulated for the years 1980-2008 using interannually varying observed SSTs is first summarized in Fig. 1. The storm tracks from the HiRAM C180 global model (Fig. 1b) are quite realistic in their geographical distribution, although there are some deficiencies apparent in the model simulation such as too few hurricane-strength tropical cyclones over the northeast Pacific basin, Bay of 
Tropical Cyclones (1980-2008)

a) OBS (2518)

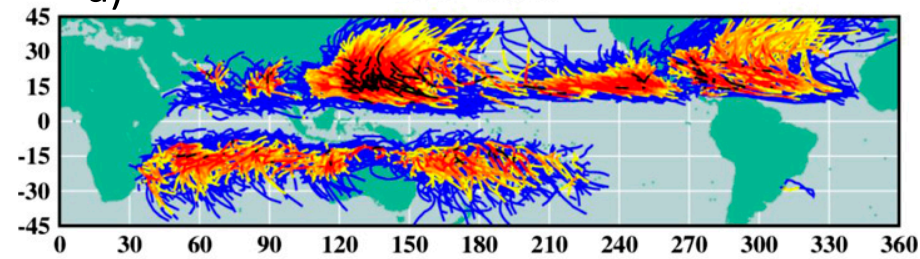

Storm Category:

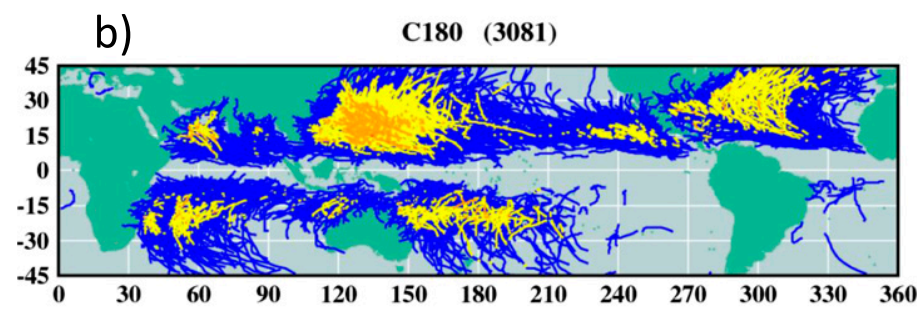

$$
\begin{array}{|ll}
- & \text { TS } \\
- & \text { HR1 } \\
- & \text { HR2 } \\
- & \text { HR3 } \\
- & \text { HR4 } \\
- & \text { HR5 }
\end{array}
$$

c) C180_HR/GFDL2012h (3031)

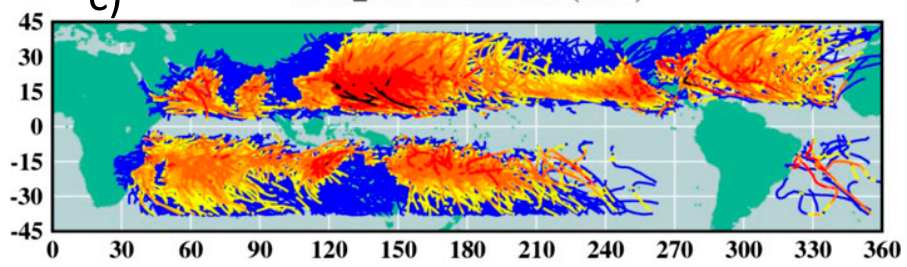

FIG. 1. (a) Tracks of observed tropical cyclones for the years 1980-2008. (b) Simulated tropical cyclone tracks for 1980-2008 obtained using HiRAM C180 running over observed interannually varying SSTs (1980-2008). (c) Simulated tropical cyclone tracks obtained using the GFDL hurricane model to resimulate tropical cyclone cases at higher resolution. These cases in (c) used the HiRAM C180 simulation to provide initial conditions and boundary conditions for the individual storm cases to the higher-resolution model. Storm categories on the Saffir-Simpson scale are depicted by the track colors, varying from tropical storm (blue) to category 5 (black; see legend). The numbers in parentheses above each panel denote the total number of storms found.

Bengal, and the southeast Indian Ocean basins. A wellknown deficiency of the HiRAM C180 model is that the upper-limit intensity for the simulated tropical cyclones is effectively about category 1 or 2 depending on the basin. While this has been partly addressed at least for the Atlantic basin, using a statistical refinement procedure (Zhao and Held 2010), in the present paper we use dynamical downscaling into the GFDL hurricane model to simulate a more realistic intensity distribution for the present-day climate. The map of simulated tracks following the second downscaling step (Fig. 1c) shows a much better agreement with observations for intense hurricanes than the HiRAM simulation, although even for the higher-resolution model a clear deficiency (underestimate) of the number of category 5 tropical cyclones remains.

Tropical cyclone annual count statistics globally and by basin for the model versus observations are summarized in Table 2. The HiRAM model simulates more total tropical cyclones (categories $0-5$, or at least tropical storm strength) than observed (106 vs 87 per year), despite having criteria for counting as a tropical cyclone that are stricter for the model (i.e., 3-day duration at tropical storm strength required) than for observations. There is a slight reduction in the number of tropical cyclones in the GFDL hurricane model downscaling simulations compared to the host HiRAM model (104 vs 106 per year), which is mostly caused by tropical cyclone cases failing to develop or lasting fewer than three days at tropical storm strength in the hurricane model downscaling runs. A few downscaling cases failed because the case occurred too close to the boundary of the regional model. The hurricane model simulates more hurricanes (i.e., total hurricanes or categories $1-5$, also called cat $1-5 ; 89$ vs 48 per year) and major hurricanes (defined as categories 3-5, or cat $3-5$; 42 vs 23 per year) than observed, but fewer very intense hurricanes (i.e., categories 4 and 5 or cat $4-5 ; 13$ 
TABLE 2. Tropical cyclone frequency statistics from downscaling experiments using observed SSTs for 1980-2006. Means are the annual counts for various storm categories. Correlations are for the observed vs modeled interannual variations. Bold correlation entries are significantly greater than zero at the 0.05 level (one-sided test), assuming individual years are temporally independent (i.e., exceed a critical value of 0.32 ). "Cat" refers to the Saffir-Simpson intensity category (1-5) with "cat 0" signifying less than hurricane strength.

\begin{tabular}{|c|c|c|c|c|c|c|c|}
\hline Variable & Global & $\begin{array}{l}\text { North } \\
\text { Atlantic }\end{array}$ & $\begin{array}{c}\text { Northeast } \\
\text { Pacific }\end{array}$ & $\begin{array}{c}\text { Northwest } \\
\text { Pacific }\end{array}$ & $\begin{array}{l}\text { North } \\
\text { Indian }\end{array}$ & $\begin{array}{l}\text { South } \\
\text { Indian }\end{array}$ & $\begin{array}{c}\text { Southwest } \\
\text { Pacific }\end{array}$ \\
\hline \multicolumn{8}{|l|}{ No. tropical cyclones (cat $0-5$ ) } \\
\hline Observed mean & 86.7 & 11.9 & 16.5 & 26.6 & 4.8 & 16.8 & 10.1 \\
\hline C180 mean & 105.5 & 13.0 & 18.6 & 35.1 & 6.0 & 18.1 & 14.6 \\
\hline Hurr. model mean & 104.1 & 12.7 & 18.2 & 34.9 & 5.8 & 18.0 & 14.5 \\
\hline Correlation: C180 vs obs. & 0.08 & 0.48 & 0.51 & 0.49 & 0.06 & 0.09 & 0.23 \\
\hline $\begin{array}{l}\text { Correlation: Hurr. model vs obs. } \\
\text { No. hurricanes (cat } 1-5)\end{array}$ & 0.06 & 0.47 & 0.50 & 0.49 & 0.15 & 0.09 & 0.21 \\
\hline Observed mean & 48.0 & 6.6 & 9.1 & 17.0 & 1.4 & 8.7 & 5.2 \\
\hline C180 mean & 34.8 & 4.6 & 3.5 & 16.9 & 1.0 & 4.2 & 4.5 \\
\hline Hurr. model mean & 88.6 & 10.0 & 15.1 & 31.0 & 4.8 & 15.2 & 12.5 \\
\hline Correlation: $\mathrm{C} 180$ vs obs. & -0.08 & 0.65 & 0.29 & 0.28 & 0.09 & -0.08 & -0.11 \\
\hline $\begin{array}{l}\text { Correlation: Hurr. model vs obs. } \\
\text { No. hurricanes (cat 3-5) }\end{array}$ & 0.06 & 0.53 & 0.58 & 0.41 & 0.30 & 0.15 & 0.13 \\
\hline Observed mean & 23.4 & 2.6 & 4.3 & 9.2 & 0.6 & 4.5 & 2.3 \\
\hline C180 mean & 0.0 & 0.0 & 0.0 & 0.0 & 0.0 & 0.0 & 0.0 \\
\hline Hurr. model mean & 42.4 & 3.5 & 5.8 & 18.2 & 2.1 & 6.4 & 6.4 \\
\hline Correlation: $\mathrm{C} 180$ vs obs. & -0.39 & 0.0 & 0.0 & -0.26 & 0.0 & 0.0 & 0.0 \\
\hline $\begin{array}{l}\text { Correlation: Hurr. model vs obs. } \\
\text { No. hurricanes (cat } 4-5 \text { ) }\end{array}$ & 0.27 & 0.52 & 0.75 & 0.28 & 0.29 & -0.10 & -0.21 \\
\hline Observed mean & 15.3 & 1.6 & 2.7 & 6.9 & 0.4 & 2.6 & 1.2 \\
\hline C180 mean & 0.0 & 0.0 & 0.0 & 0.0 & 0.0 & 0.0 & 0.0 \\
\hline Hurr. model mean & 12.7 & 1.1 & 0.9 & 7.6 & 0.5 & 1.0 & 1.7 \\
\hline Correlation: C180 vs obs. & 0.0 & 0.0 & 0.0 & 0.0 & 0.0 & 0.0 & 0.0 \\
\hline Correlation: Hurr. model vs obs. & 0.08 & 0.40 & 0.24 & 0.21 & -0.25 & -0.07 & -0.01 \\
\hline
\end{tabular}

vs 15 per year) than observed. It is notable that the hurricane model has a slight low bias in cat 4-5 hurricane frequency despite an overall high bias in the total number of tropical cyclones and hurricanes in the simulation. [Note that for convenience, we use the term "hurricane" here to describe tropical cyclones with intensities greater than $33 \mathrm{~m} \mathrm{~s}^{-1}$ regardless of their basin of occurrence.]

Table 2 also contains a summary of the correlation between the observed and simulated time series of annual storm counts of various classes, globally and for each basin. For both HiRAM and the GFDL hurricane model, the total tropical cyclone (defined as categories $0-5$, or cat $0-5$ ) simulated numbers are significantly correlated $(r>0.31)$ to observed in the North Atlantic, northeast Pacific, and northwest Pacific basins, but this is not the case for the remaining three basins or the global mean series. For higher-intensity classes (e.g., hurricanes, major hurricanes, and cat 4-5 hurricanes) the GFDL hurricane model simulations are significantly correlated with observations for the same three basins for (cat 1-5) hurricanes (North Atlantic, northeast Pacific, and northwest Pacific); for major (cat 3-5) hurricanes, the North Atlantic and northeast Pacific are significantly correlated; and for very intense hurricanes (cat 4-5), only the North Atlantic is significantly correlated with observations. The highest annual correlation found in our experiments was $r=0.75$ for major hurricanes in the northeast Pacific basin.

The simulated frequency distributions of tropical cyclone intensity (Fig. 2) show reasonable agreement with observations for the North Atlantic and northwest Pacific basins, except for wind speeds greater than $65 \mathrm{~m} \mathrm{~s}^{-1}$. There is some disagreement between two different observational datasets for the northwest Pacific basin, with the JTWC dataset having a greater occurrence of intense typhoons $\left(>55 \mathrm{~m} \mathrm{~s}^{-1}\right)$ than the Japanese Meteorological Agency (JMA) dataset, as has been noted in previous studies (e.g., Song et al. 2010). The model's distribution is closer to the JMA estimates, especially for storms exceeding $50 \mathrm{~m} \mathrm{~s}^{-1}$ maximum intensity. Nonetheless, on the basis of these comparisons and available information on the observed datasets, we suspect that our model is underestimating the occurrence of very intense typhoons in the northwest Pacific basin. The modeled intensity distribution is more peaked than the observed in the northeast Pacific, south Indian, north Indian, and southwest Pacific basins, with an unrealistically peaked distribution mode around $50 \mathrm{~m} \mathrm{~s}^{-1}$. The pronounced bimodal distribution 
a) North Atlantic

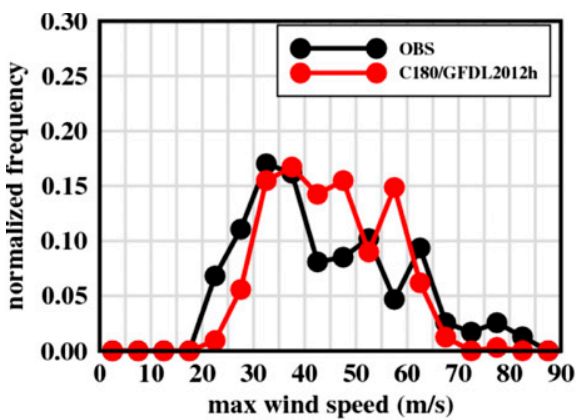

c) Northwest Pacific

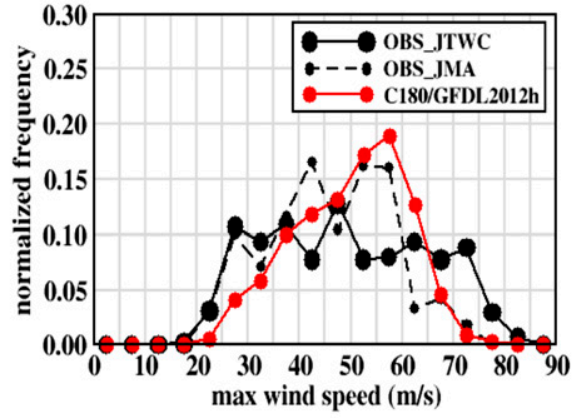

e) South Indian Ocean

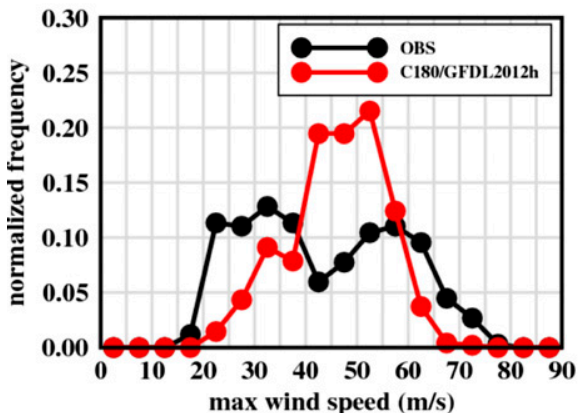

b) Northeast Pacific

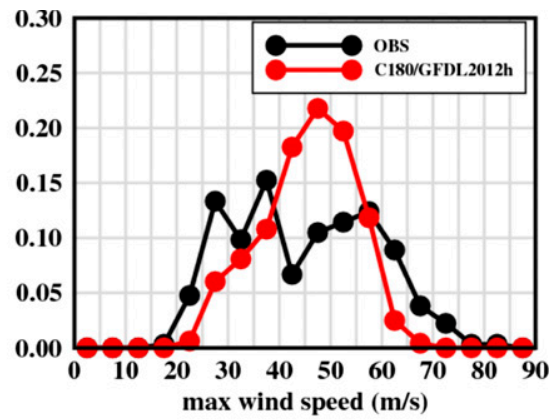

d) North Indian Ocean

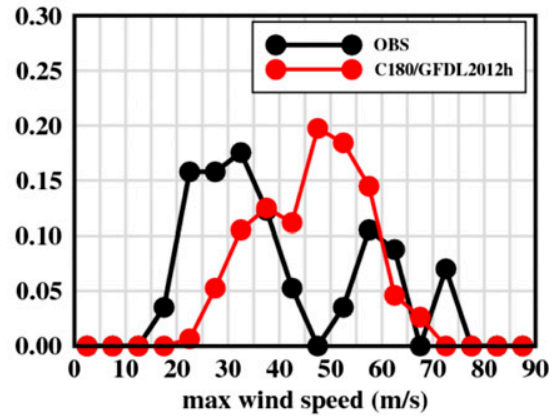

f) Southwest Pacific

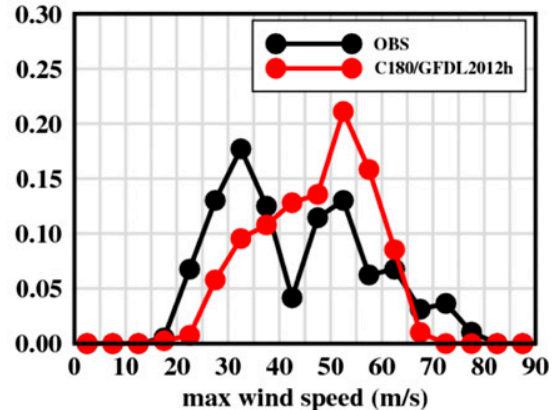

FIG. 2. Comparison of observed (black) and simulated (red) distributions of tropical cyclone intensity (maximum surface winds speed in $\mathrm{m} \mathrm{s}^{-1}$ ) based on one value per storm at the time of the storm's maximum intensity (1980-2008 observations or SST conditions for the model). Distributions are shown for various tropical cyclone basins. Simulated results were obtained using the GFDL hurricane model for the final downscaling step. For the northwest Pacific basin, observed distributions from two alternative data sources are included [Joint Typhoon Warning Centers (JTWC) and Japanese Meteorological Agency (JMA)]. Distributions are normalized to relative frequency by dividing by the number of storms in each histogram bin by the total number of storms observed or simulated for the basins.

for observations in the north Indian basin is not reproduced by our model.

Figure 3 shows the joint distribution of simulated intensities as a scatterplot of central pressures and maximum wind speeds. While the HiRAM C180 model (green dots) simulates relatively low central pressures-at least as low as are simulated by the higher-resolution GFDL hurricane model (aqua dots) - the HiRAM C180 does not simulate maximum surface wind speeds above about $55 \mathrm{~m} \mathrm{~s}^{-1}$ in our experiments. This contrasts with the hurricane model, which simulates maximum surface wind speeds in some cases of over $70 \mathrm{~m} \mathrm{~s}^{-1}$ for present-day 


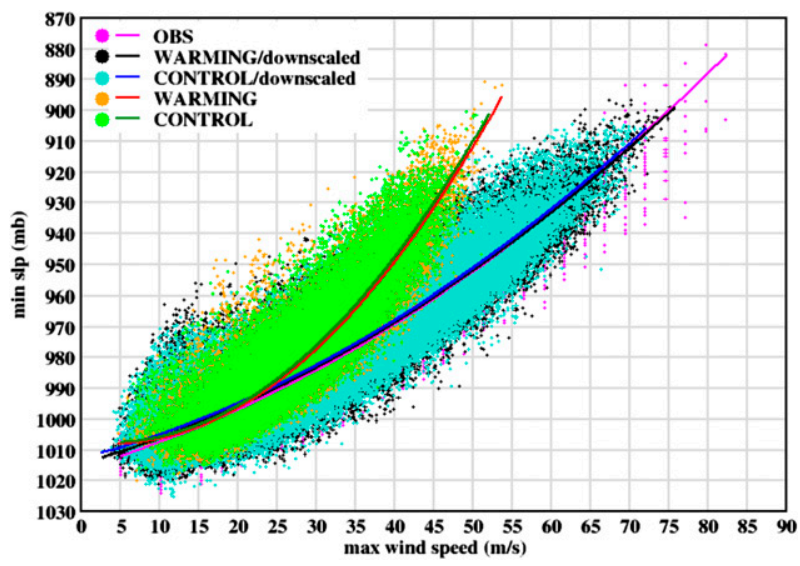

FIG. 3. Scatterplot of tropical cyclone maximum wind speeds $\left(\mathrm{m} \mathrm{s}^{-1}\right)$ vs central minimum pressure $(\mathrm{hPa}$ or $\mathrm{mb})$. Dots denote single occurrences for observations (purple), GFDL hurricane model control runs (aqua) and late-twenty-first-century projection runs (black), or HiRAM C180 control runs (green) and latetwenty-first-century projections (orange). Observations are shown by the purple dots and curve. The smooth curves are least squares quadratic best-fit lines through the data for the various cases. Note that the observations are shown for the period 2001-12, while the "Control" simulations shown are based on climatological SST conditions for 1982-2005.

conditions. The purple and blue solid curves in Fig. 3 show the nonlinear (quadratic polynomial) best-fit curves for the observed and simulated (GFDL hurricane model) present-day wind-pressure data. These curves show that the observed (global) wind-pressure relationship is well captured in the GFDL hurricane model.

Figure 4 compares the modeled and observed areaaveraged rainfall, as a function of distance to the track center, for the rainiest $10 \%$ of storms, following the methodology of Villarini et al. (2014), which focused on storms within $30^{\circ}$ of the equator to reduce the influence of extratropical stages on the results. Under this approach, the $10 \%$ of storms having the highest average daily rainfall accumulation within a $5^{\circ}$ radius around the storm center were composited for both models and observations, a procedure that tends to focus on the storms with relatively high potential rainfall impact. The model composite is compared to observations from the Tropical Rainfall Measuring Mission (TRMM) Multisatellite Precipitation Analysis (TMPA; Huffman et al. 2007). The modeled distribution exceeds the TRMM estimate, with a peak value of up to $350 \mathrm{~mm} \mathrm{day}^{-1}$ or more at a radius of about $50-100 \mathrm{~km}$ from the storm; this compares to a peak of 150 to $250 \mathrm{~mm} \mathrm{day}^{-1}$ for TRMM. For North Atlantic landfalling cases, the GFDL hurricane model rainfall has been compared with TRMM estimates and observed rain gauge values (not shown; Tuleya et al. 2007), which also indicated the hurricane model overestimating rainfall-and the TRMM underestimating rainfall-near the storm center compared to gauge values. The precipitation distribution for a composite of tropical cyclones from HiRAM (not shown) has a peak of about $200-270 \mathrm{~mm}$ day $^{-1}$.

Following from recent work exploring outer storm size (Chavas and Emanuel 2010; Kim et al. 2014), we estimate the radius of $12 \mathrm{~m} \mathrm{~s}^{-1}$ surface winds $\left(r_{12}\right)$ from the radial profile of the azimuthal wind at the lowest model level for each time step. The azimuthal component of the wind is chosen because it is the quantity predicted by theory to decay to zero at some finite radius (Emanuel 2004; Chavas et al. 2015); this property also offers practical benefit when estimating the radius of relatively small wind speeds in the outer circulation. For the purposes of direct comparison with observations, $r_{12}$ is estimated following the methodology underlying the QuikSCAT-based radial wind profile database (QSCAT-R) detailed in Chavas and Vigh (2014) and summarized here. Storm latitude, longitude, intensity, and translation vector are taken from track data (model: collocated 6-hourly output; observations: HURDAT2 in the Atlantic and northeast Pacific basins, JTWC in all other basins interpolated to each QuikSCAT pass time). To match QuikSCAT observations, which are only available over water, model data over land are masked out. Next, from each available tropical cyclone fix, radial wind profiles are calculated by first subtracting from all data points an estimate of the background flow vector (Lin and Chavas 2012) and then decomposing the flow field into its azimuthal and radial components in a polar coordinate system relative to the storm center. All data are then averaged within annuli of width $\Delta r=18.55 \mathrm{~km}$ (i.e., $1 / 6^{\circ}$ ) for the model and $\Delta r=12.5 \mathrm{~km}$ for observations, moving radially outwards from the center in increments of $\Delta r / 4$. Finally, $r_{12}$ is estimated moving radially outwards from the radius of maximum winds.

Additionally, because accurate radial profile estimation depends on having sufficient azimuthal data coverage, for both observations and model simulations we define a data asymmetry parameter as a function of radius, denoted $\xi$, as the magnitude of the vector mean of all grid point distance vectors from the center. For small $\Delta r / r, \xi=0$ for data with perfect azimuthal symmetry (lower uncertainty) and $\xi=1$ in the case of a single data point (higher uncertainty). This parameter may be used to select subsets of $r_{12}$ values with sufficient azimuthal coverage and thus lower uncertainty.

For a consistent comparison between model and observations, we apply an identical set of filters to both datasets: 1) Vmax $>25 \mathrm{~m} \mathrm{~s}^{-1}$ to avoid particularly weak storms, 2) $\xi\left(r_{12}\right) \leq 0.5$, and 3) storm center latitude 

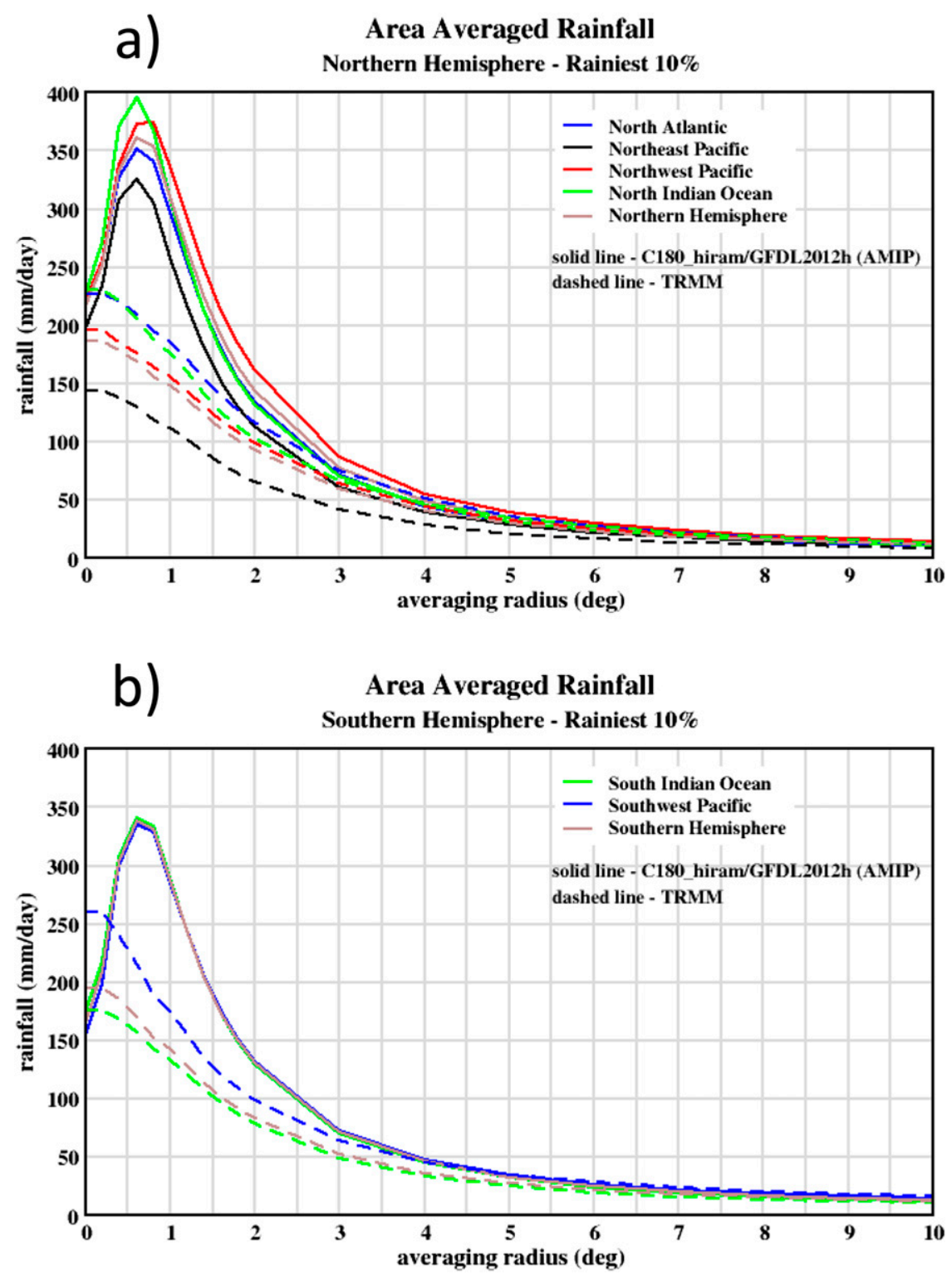

FIG. 4. Profiles of tropical cyclone precipitation rates $\left(\mathrm{mm} \mathrm{day}^{-1}\right)$, averaged from the storm center to the radius indicated on the abscissa (in degrees) based on the lifetime-average precipitation rate for the $10 \%$ rainiest tropical cyclones (see text). Results are compared for observations from TRMM satellite measurements (dashed) and the GFDL hurricane model (solid) for downscaling experiments based initially on HiRAM C180 global atmospheric simulations obtained using observed interannually varying SSTs (1980-2008). Results are shown for the (a) Northern and (b) Southern Hemisphere for various tropical cyclone basins (colors; see legend).

$\varphi \leq 30^{\circ}$ to remove cases undergoing extratropical transition. Additionally, cases are removed if the storm center is over land or if $r_{12}<50 \mathrm{~km}$; the latter is imposed because accurate decomposition of the flow vectors at small radii is increasingly sensitive to the accuracy of the storm center position, which is subject to errors particularly in observational analysis. The conclusions presented below are not sensitive to variations in these parameters. The resulting sample sizes are $N=1324$ (observations), $N=$ 40282 (control), and $N=32998$ (late twenty-first century). Finally, observational data are binned into basins defined by identical boundaries as used for the model.

Figure 5 displays the probability distributions of $r_{12}$ for observations and both model simulations, shown 

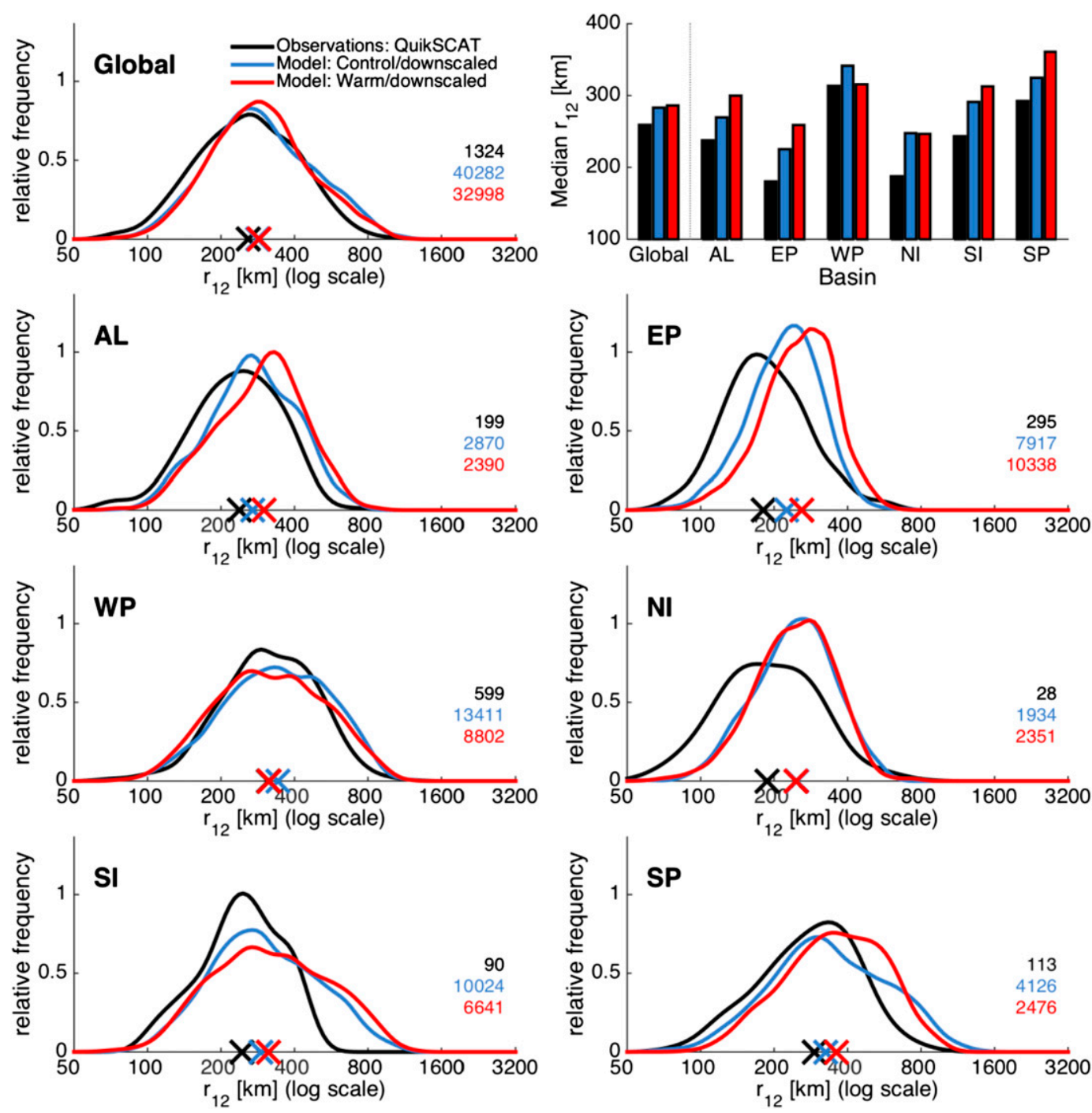

FIG. 5. Relative frequency of tropical cyclone size, globally and for various tropical cyclone basins (AL $=$ North Atlantic; $\mathrm{EP}=$ northeast Pacific; $\mathrm{WP}=$ northwest Pacific; $\mathrm{NI}=$ north Indian; $\mathrm{SI}=$ south Indian; and SP $=$ southwest Pacific). The size metric, $r_{12}$, is the radius at which the azimuthal-mean azimuthal wind speed decreases to $12 \mathrm{~m} \mathrm{~s}^{-1}$. Black curves depict observed estimates based on QuikSCAT satellite measurements; blue and red curves depict distributions based on model simulations for control (present day; blue) or warm climate (late twenty-first century; red) conditions. The " $\mathrm{X}$ " marks on each diagram denote median values. The numbers listed on each diagram denote the number of cases analyzed. The top right panel shows the global and interbasin variation of median tropical cyclone sizes for this metric. Control runs are based on climatological SSTs for 1982-2005. See text for further details.

both globally and within each basin. First and foremost, the control (present-day) simulation performs well in reproducing the observations, both in terms of distribution shape, which is approximately lognormal [similar to the results of Chavas and Emanuel (2010)], and variability. Indeed, the interbasin variability in median $r_{12}$ is surprisingly well captured in the model (Fig. 5, upper right panel), albeit with a slightly high bias that is consistent across all basins; the model median overestimates the observed value by $9.3 \%$ globally, with a range from
$8.9 \%$ in the northwest Pacific to $32 \%$ in the north Indian Ocean. Moreover, the model also adequately captures intrabasin variability as measured by the coefficient of variation $(\mathrm{CV}=\sigma / \mu)$, whose magnitude of 0.53 globally compares well with the observed value of 0.49 , indicating significant variability in storm size within basins as is seen in observations.

The above comparisons of simulated storm tracks, intensity distribution, rainfall, and storm size distributions indicate that for all metrics there is room for 
TABLE 3. Tropical cyclone activity (percent change) statistics from downscaling experiments for CMIP5 multimodel ensembles (future vs present day). The future scenarios use RCP4.5 averaged conditions for late twenty-first century and are compared to the "present-day", simulations for 1982-2005 climatological SST conditions. "Cat" refers to Saffir-Simpson intensity category (1-5) with "cat 0" signifying less than hurricane strength. Rain rate is the average rain rate within $100 \mathrm{~km}$ of the storm center, including all tropical cyclones (not just $10 \%$ rainiest). PDI is power dissipation index in units of $10^{9} \mathrm{~m}^{3} \mathrm{~s}^{-2}$. "Hur (wind $>65$ )" refers to hurricanes with surface wind speeds greater than or equal to $65 \mathrm{~m} \mathrm{~s}^{-1}$. "Maxwnd_tc" and "maxwnd_hur" are percent changes of mean lifetime-maximum intensities for all tropical cyclones (wind speed $>17.5 \mathrm{~m} \mathrm{~s}^{-1}$ ) or hurricanes (wind speed $>33 \mathrm{~m} \mathrm{~s}^{-1}$ ). The $p$ values, for a null hypothesis of no change from present to future, are given in the line below each percent change entry. These use a two-sided Mann-Whitney-Wilcoxon test for all frequency or days-of-occurrence metrics, and a one-sided test (for increase) for the intensity and rain rate metrics. Bold values indicate significance at the $p<0.05$ level. "Inf" refers to cases where no occurrences were simulated in the present-day run while some were simulated in the future runs, indicating an infinite percent increase.

\begin{tabular}{|c|c|c|c|c|c|c|c|}
\hline Variable & Global & $\begin{array}{c}\text { North } \\
\text { Atlantic }\end{array}$ & $\begin{array}{l}\text { Northeast } \\
\text { Pacific }\end{array}$ & $\begin{array}{c}\text { Northwest } \\
\text { Pacific }\end{array}$ & $\begin{array}{l}\text { North } \\
\text { Indian }\end{array}$ & $\begin{array}{l}\text { South } \\
\text { Indian }\end{array}$ & $\begin{array}{c}\text { Southwest } \\
\text { Pacific }\end{array}$ \\
\hline No. of TC (cat $0-5$ ) & -16.4 & -9.4 & 16.3 & -34.5 & 19.5 & -26.1 & -36.6 \\
\hline$p$ value & $<\mathbf{0 . 0 1}$ & 0.39 & $\mathbf{0 . 0 2}$ & $<\mathbf{0 . 0 1}$ & 0.07 & $<\mathbf{0 . 0 1}$ & $<\mathbf{0 . 0 1}$ \\
\hline No. of hur (cat 1-5) & -16.6 & -17.5 & 19.3 & -31.6 & 25.6 & -28.4 & -40.6 \\
\hline$p$ value & $<\mathbf{0 . 0 1}$ & 0.16 & 0.01 & $<\mathbf{0 . 0 1}$ & 0.04 & $<\mathbf{0 . 0 1}$ & $<\mathbf{0 . 0 1}$ \\
\hline No. of hur (cat 3-5) & 1.8 & 2.7 & 83.7 & -16.9 & 21.7 & -8.3 & -50.6 \\
\hline$p$ value & 0.72 & 0.76 & $<\mathbf{0 . 0 1}$ & $<\mathbf{0 . 0 1}$ & 0.14 & 0.42 & $<\mathbf{0 . 0 1}$ \\
\hline No. of hur (cat 4-5) & 28.3 & 42.1 & 337.5 & -6.5 & 200.0 & 63.6 & -58.3 \\
\hline$p$ value & $<\mathbf{0 . 0 1}$ & 0.63 & $<\mathbf{0 . 0 1}$ & 0.59 & -0.05 & 0.07 & 0.01 \\
\hline No. of hur $($ wind $>65)$ & 59.3 & 125.0 & Inf & 16.7 & Inf & Inf & 0.0 \\
\hline$p$ value & 0.01 & 0.36 & & 0.63 & & & 1.00 \\
\hline $\mathrm{ACE}$ & -13.1 & -9.7 & 44.2 & -26.9 & 23.2 & -28.8 & -41.7 \\
\hline$p$ value & 0.15 & 0.29 & $<\mathbf{0 . 0 1}$ & $<\mathbf{0 . 0 1}$ & 0.13 & $<\mathbf{0 . 0 1}$ & $<\mathbf{0 . 0 1}$ \\
\hline PDI & -9.7 & -3.1 & 52.7 & -22.7 & 28.6 & -26.6 & -43.9 \\
\hline$p$ value & $<\mathbf{0 . 0 1}$ & 0.53 & $<\mathbf{0 . 0 1}$ & $<0.01$ & 0.08 & $<\mathbf{0 . 0 1}$ & $<\mathbf{0 . 0 1}$ \\
\hline maxwnd_ts & 3.6 & 0.4 & 8.2 & 7.4 & 3.4 & 1.8 & -5.6 \\
\hline$p$ value & $<\mathbf{0 . 0 1}$ & 0.41 & $<\mathbf{0 . 0 1}$ & $<\mathbf{0 . 0 1}$ & 0.07 & 0.20 & 0.98 \\
\hline maxwnd_hur & 4.1 & 4.5 & 7.8 & 5.5 & 1.6 & 3.3 & -3.1 \\
\hline$p$ value & $<\mathbf{0 . 0 1}$ & 0.04 & $<\mathbf{0 . 0 1}$ & $<\mathbf{0 . 0 1}$ & 0.23 & $\mathbf{0 . 0 3}$ & 0.88 \\
\hline Cat $4-5$ days & 34.5 & 175.4 & 478.1 & 9.7 & 405.0 & 55.4 & -52.5 \\
\hline$p$ value & $<\mathbf{0 . 0 1}$ & 0.14 & $<\mathbf{0 . 0 1}$ & 0.50 & 0.04 & 0.39 & $\mathbf{0 . 0 3}$ \\
\hline Rain rate_tc (cat $0-5$ ) & 14.3 & $\mathbf{1 7 . 3}$ & 17.2 & 20.8 & 10.5 & 8.5 & -1.2 \\
\hline$p$ value & $<0.01$ & $<\mathbf{0 . 0 1}$ & $<0.01$ & $<0.01$ & 0.01 & $\mathbf{0 . 0 3}$ & 0.66 \\
\hline Rain rate hur (cat $1-5$ ) & 13.4 & 20.5 & 14.4 & 15.5 & 12.8 & 11.1 & 3.5 \\
\hline$p$ value & $<\mathbf{0 . 0 1}$ & $<\mathbf{0 . 0 1}$ & $<\mathbf{0 . 0 1}$ & $<\mathbf{0 . 0 1}$ & $<\mathbf{0 . 0 1}$ & $<\mathbf{0 . 0 1}$ & 0.58 \\
\hline Rain rate hur (cat $3-5$ ) & 8.8 & 14.0 & 9.7 & 9.7 & 10.8 & 6.1 & 10.6 \\
\hline$p$ value & $<\mathbf{0 . 0 1}$ & 0.02 & $<\mathbf{0 . 0 1}$ & $<\mathbf{0 . 0 1}$ & $<\mathbf{0 . 0 1}$ & $<\mathbf{0 . 0 1}$ & 0.65 \\
\hline Rain rate hur (cat 4-5) & 7.7 & 9.4 & 11.4 & 8.7 & 21.4 & -1.5 & 15.3 \\
\hline$p$ value & $<\mathbf{0 . 0 1}$ & 0.13 & $<\mathbf{0 . 0 1}$ & $<\mathbf{0 . 0 1}$ & 0.06 & 0.54 & 0.93 \\
\hline Delta SST $\left({ }^{\circ} \mathrm{C}\right)$ & & 1.546 & 1.685 & 1.567 & 1.551 & 1.384 & 1.145 \\
\hline
\end{tabular}

improvement, but the results suggest that the model simulation of present-day tropical cyclone activity is adequate to justify an exploration of our downscaling framework's response to climate change scenarios for the late twenty-first century, keeping in mind the deficiencies noted in this section.

\section{Late-twenty-first-century climate change scenarios}

\section{a. Tropical cyclone genesis frequency changes}

The changes in tropical cyclone genesis frequency for the CMIP5/RCP4.5 late-twenty-first-century scenario are summarized for each basin and globally in Table 3 (see also Fig. 1). Globally there is a reduction in tropical cyclone genesis $(-16 \%)$, consistent with previous global warming studies using the HiRAM C180 model (e.g., Zhao et al. 2009), and with numerous pre-CMIP5 studies by various groups using global atmospheric or coupled models (e.g., Knutson et al. 2010; Christensen et al. 2013). The projected reduction is generally consistent with a more recent analysis of CMIP5 climate model projections using an empirical tropical cyclone detection method (Tory et al. 2013), who found a 7\%-28\% reduction in tropical cyclone frequency across eight CMIP5 models that had reasonable present-day inferred tropical cyclone climatology. However, our model's simulated decrease is in contrast to the $10 \%-40 \%$ global increase in late-twenty-first-century tropical cyclone 
frequency projected by Emanuel (2013) using a statisticaldeterministic framework with CMIP5 RCP8.5 projections. The projections in Emanuel (2013) and Tory et al. for the late twenty-first century used subsets of CMIP5 models that were different from those included in our study, and both of those studies were based on a downscaling of the stronger climate forcing (RCP8.5) scenario.

As shown by Held and Zhao (2011), the reduction in tropical cyclone frequency in HiRAM includes a contribution from the direct effect of increasing atmospheric $\mathrm{CO}_{2}$ (with SST held fixed). Their finding and that of Zhao et al. (2013) confirm the earlier findings of Yoshimura and Sugi (2005). Zhao et al. (2013) show that for the seven models they examined, the $\mathrm{CO}_{2}$-induced reduction in genesis frequency is even more robust across models than the reduction in genesis frequency associated with a 2-K uniform SST warming alone. The physical mechanism producing the global reduction in tropical cyclone frequency in the various model projections is still unclear, but possible mechanisms include a slowing of the large-scale tropical circulation (Sugi et al. 2002; Bengtsson et al. 2007) due to mechanisms as discussed in Knutson and Manabe (1995) and Held and Soden (2006) or increases in the saturation deficit between the surface and middle troposphere (Emanuel et al. 2008). A recent discussion of the frequency reduction issue is given in Sugi et al. (2012).

The reduced global genesis frequency in the RCP4.5 experiments is reflected in a reduction in four of the six major tropical cyclone basins (North Atlantic, northwest Pacific, south Indian, and southwest Pacific). An increase is simulated for the northeast Pacific and north Indian Ocean basins. An increase is also simulated for the South Atlantic basin (Fig. 1), although this basin is a special case where the historical occurrence is quite rare (e.g., Catarina in 2004); moreover, the HiRAM C180 seems to overestimate present-day genesis rate there (cf. Figs. 1a and 1b), implying that quantitative projections of increases for this basin should be viewed with caution.

\section{b. Storm intensity changes}

Figure 3 shows that both HiRAM and the GFDL hurricane model have a slightly expanded range of high intensities for the warmer climate conditions, considering all basins as an aggregate global distribution. This is shown by the occurrence of black dots and orange dots on Fig. 3 at the upper right edges of the scatterplot region, extending beyond the green and aqua-colored dot regions, respectively.

The influence of climate warming on the simulated intensity distributions is seen more clearly in Fig. 6. This

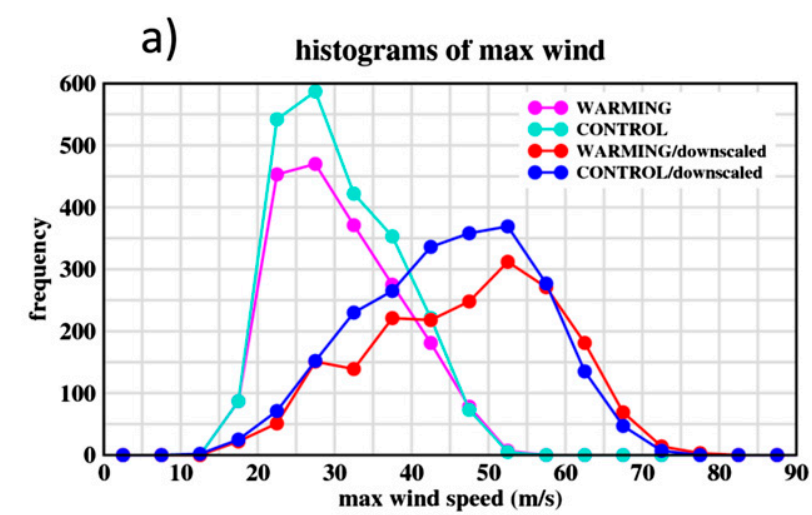

b) normalized histograms of $\max$ wind

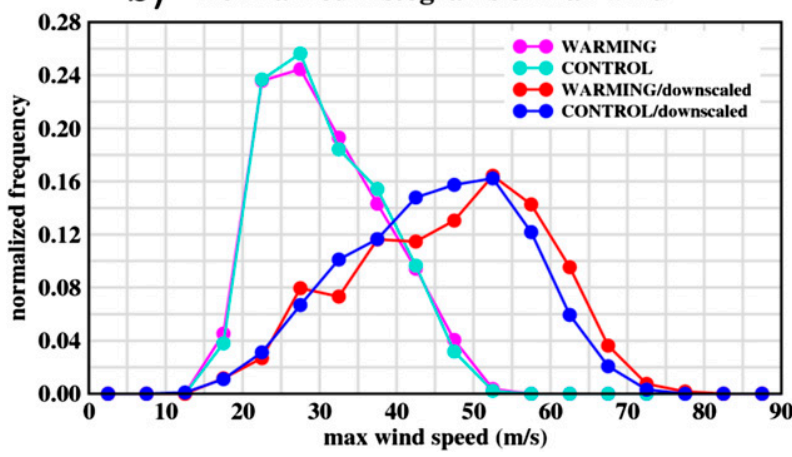

FIG. 6. As in Fig. 2, but comparing (a) total or (b) normalized frequency distributions of maximum surface wind intensities $\left(\mathrm{m} \mathrm{s}^{-1}\right.$, one value per storm) for simulations using present-day (control) or CMIP5/RCP4.5 late-twenty-first-century (warming) climate conditions (see legend) for all TC basins. Simulation results are shown for HiRAM C180 (purple, aqua) and for the GFDL hurricane model downscaling (red, dark blue).

figure compares the globally aggregated distributions of tropical cyclone intensities for the present-day and warm-climate conditions, for both the HiRAM C180 and GFDL hurricane models. Despite the global reduction in number of tropical cyclones for the warmer climate, the GFDL hurricane model shows an increase in the number of very intense tropical cyclones, with a "cross-over point" from decreased to increased frequency at an intensity of around $55-60 \mathrm{~m} \mathrm{~s}^{-1}$. This increased occurrence of higher maximum intensities is difficult to discern in the HiRAM C180 distribution, even after the distributions are normalized by the total number of storms (Fig. 6b). On the other hand, for the GFDL hurricane model, such a normalization of the distribution makes the increased relative occurrence at high intensity much more apparent. The average intensity of all tropical cyclones (cat 0-5) in the GFDL hurricane model increases by $3.6 \%$ globally (Table 3 ), while the average intensity of all tropical cyclones (cat $1-5)$ that exceed hurricane intensity $\left(33 \mathrm{~m} \mathrm{~s}^{-1}\right)$ increases 
a) Present Day Simulation: 244 Cat 4-5 storms
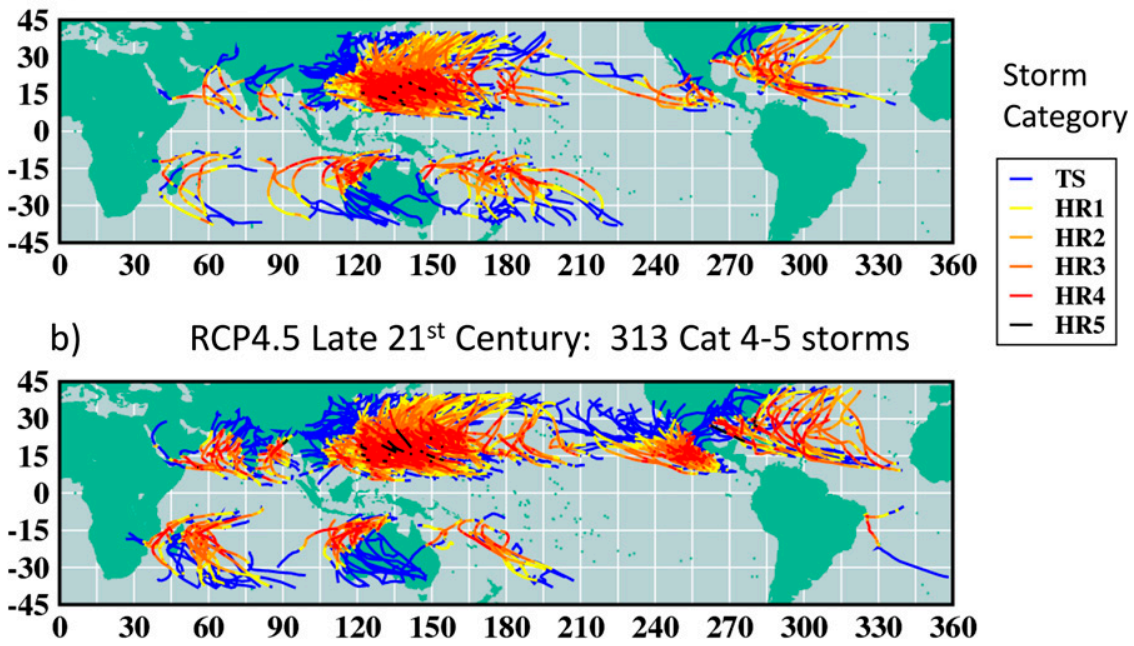

FIG. 7. Tracks of simulated cat 4-5 tropical cyclones for (a) present-day or (b) late-twentyfirst-century (RCP4.5; CMIP5 multimodel ensemble) conditions. Simulated tropical cyclone tracks were obtained using the GFDL hurricane model to resimulate (at higher resolution) the tropical cyclone cases originally obtained from the HiRAM C180 global mode. Storm categories or intensities are shown over the lifetime of each storm, according to the Saffir-Simpson scale. The categories are depicted by the track colors, varying from tropical storm (blue) to category 5 (black; see legend).

by $4.1 \%$. For HiRAM, the average intensity of all tropical cyclones increases by $0.4 \%$ globally, while the average intensity of all tropical cyclones that exceed hurricane intensity increases by $0.7 \%$. The larger intensity increases we find for the GFDL hurricane model (compared to HiRAM) are relatively more consistent with previous studies for the Atlantic basin (Hill and Lackmann 2011; Knutson et al. 2013) and for the globe (Oouchi et al. 2006; Murakami et al. 2012b) that used relatively high-resolution modeling frameworks (2-9-km grid spacing for the Atlantic studies; $20-\mathrm{km}$ grid spacing in Oouchi et al. and Murakami et al.).

The results in Table 3 indicate that the projected intensity increases noted above for the global distributions do not occur in all basins. For tropical cyclones exceeding tropical storm or hurricane intensity (greater than 17.5 or $33 \mathrm{~m} \mathrm{~s}^{-1}$, respectively), the average intensity decreases in the southwest Pacific basin by $-5.6 \%$ and $-3.1 \%$, respectively. The average intensity of hurricanes increases in the Atlantic by $+4.5 \%$, although the average intensity of all tropical cyclones combined barely changes $(+0.4 \%)$ in the Atlantic basin. The basin with the most pronounced intensity increases is the northeast Pacific $(+8 \%$ for all tropical cyclones and also for hurricanes). The northwest Pacific basin also has statistically significant projected maximum intensity increases of $+7 \%$ for all tropical cyclones and $+6 \%$ for hurricanes.

\section{c. Storm track and occurrence changes}

While tropical cyclone genesis rates are important, metrics that are even more closely tied to impacts include the storm tracks and maps of storm occurrence rates. Additionally, a small number of very intense storms have caused a disproportionate amount of damage historically (e.g., Pielke et al. 2008). The tracks of all storms that reach at least category-4 intensity $\left(>58 \mathrm{~m} \mathrm{~s}^{-1}\right)$ in the present-day and late-twenty-first-century simulations are shown in Fig. 7. The global increase in the number of these storms is $+28 \%$ ( 244 storms in the control versus 313 storms in the late-twenty-first-century simulation). A reduction is apparent in the southwest Pacific basin ( $-58 \%$; Table 3$)$. The basin with the largest fractional increase is the northeast Pacific $(+338 \%)$ although substantial increases are also projected in the Atlantic $(+42 \%)$, north Indian $(+200 \%)$, and south Indian $(+64 \%)$ basins. Focusing on the strongest category of storm in our simulations (maximum surface wind speeds exceeding $65 \mathrm{~m} \mathrm{~s}^{-1}$ ), Table 3 shows that the global frequency increases by $59 \%$, with increases in all basins except the southwest Pacific, where there is no change in projected frequency; however, the annual number of storms of this intensity is very limited in our simulated study (increasing from 2.7 to $4.3 \mathrm{yr}^{-1}$ ).

An alternative metric that incorporates the duration of storms at category 4 and 5 intensity is the number of 
a) Present-day simulation

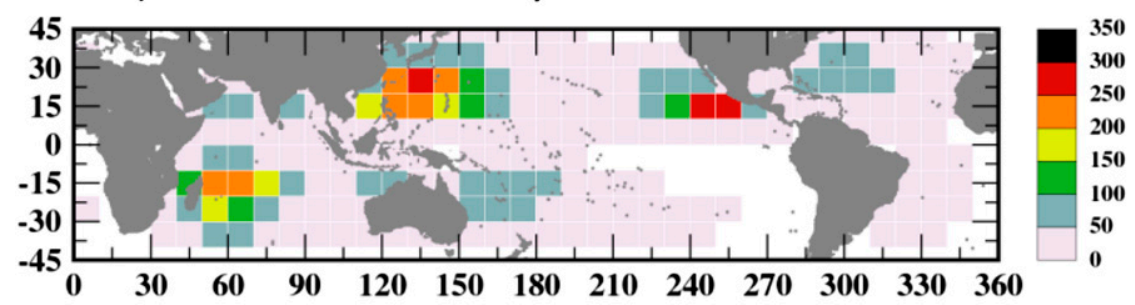

b) RCP4.5 Late $21^{\text {st }}$ Century Projection

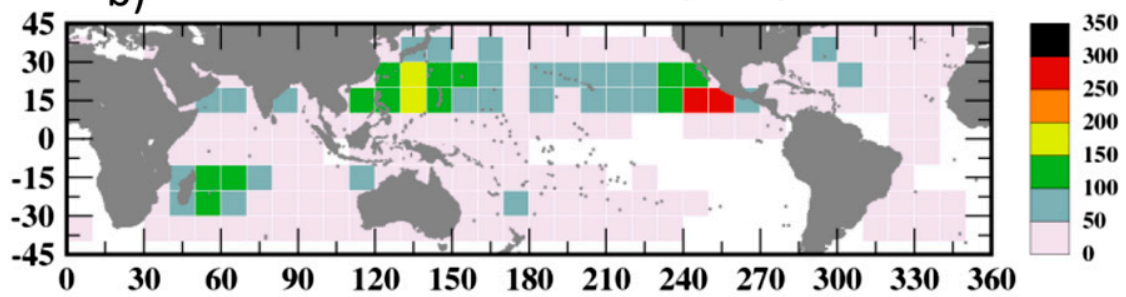

c) Late $21^{\text {st }}$ century minus present-day

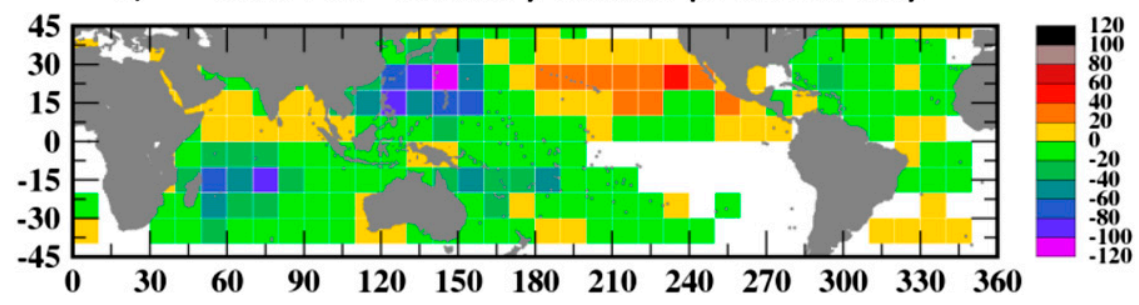

FIG. 8. Simulated occurrence of all tropical storms (tropical cyclones with winds exceeding $17.5 \mathrm{~m} \mathrm{~s}^{-1}$ ) for (a) present-day or (b) late-twenty-first-century (RCP4.5; CMIP5 multimodel ensemble) conditions; unit: storms per decade. Simulated tropical cyclone tracks were obtained using the GFDL hurricane model to resimulate (at higher resolution) the tropical cyclone cases originally obtained from the HiRAM C180 global mode. Occurrence refers to the number of days, over a 20-yr period, in which a storm exceeding $17.5 \mathrm{~m} \mathrm{~s}^{-1}$ intensity was centered within the $10^{\circ} \times 10^{\circ}$ grid region. (c) Difference in occurrence rate between late twenty-first century and present day [(b) minus (a)]. White regions are regions where no tropical storms occurred in the simulations [in (a) and (b)] or where the difference between the experiments is zero [in (c)].

cat $4-5$ days. This metric is projected to increase by $35 \%$ globally (Table 3 ), in comparison to the $24 \%$ increase in number, indicating that the average time duration per cat 4-5 storm that is spent at intensities above the category- 4 threshold is also increasing in the warm climate simulation. The sample of 244 (control) or 313 (late twenty-first century) cat 4-5 storms in our simulations is a large enough sample for us to investigate some of the regional patterns of change in occurrence. Thus, the regional patterns of changes in tropical cyclone occurrence and of cat 4-5 storm occurrence are shown in Figs. 8 and 9, respectively. Most of the northeast Pacific and north Indian Ocean have increased tropical cyclone occurrence in the late-twenty-first-century simulation (Fig. 8), while most of the remainder of the globe has a decrease. Considering cat 4-5 storm occurrence (Fig. 9), most of the north Indian Ocean, northeast Pacific, North Atlantic, and southwest Indian Ocean regions show an increase. A small region off the coast of Brazil also shows an increase but this is due to a single intense storm in the late-twenty-first-century runs (Fig. 7). The areas of decreased cat 4-5 occurrence (Fig. 9) include most of the southwest Pacific basin and parts of the eastern Indian Ocean basins. In the northwest Pacific basin, the southern section of the basin has some areas of decrease, while the northern and eastern sections of this basin show increases suggestive of an expansion of the range of cat 4-5 occurrence. In terms of percent changes in cat 4-5 occurrence, there are also large percent increases projected for a number of basins (Table 3), especially in some basins where the rate of occurrence is relatively small in the control climate. The absolute changes of cat 


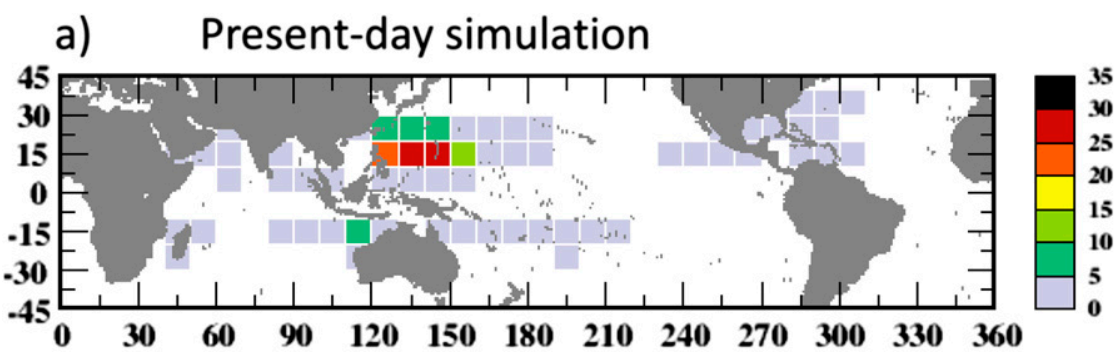

b) RCP4.5 Late $21^{\text {st }}$ Century Projection

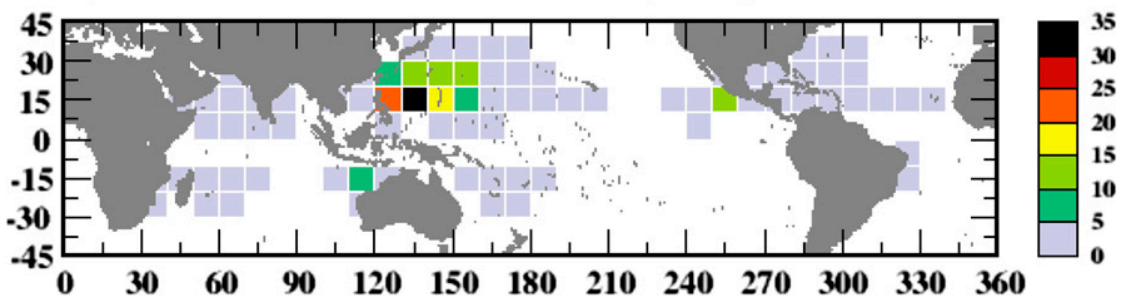

c) Late $21^{\text {st }}$ century minus present-day

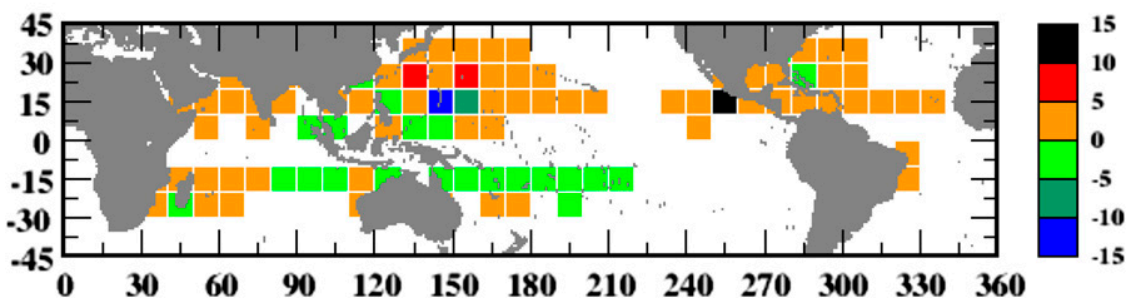

FIG. 9. As in Fig. 8, but for tropical cyclones of at least category-4 intensity (surface winds of at least $59 \mathrm{~m} \mathrm{~s}^{-1}$ ).

4-5 storm occurrence (in storms per decade; Fig. 9) are more evenly distributed across the tropics. A number of regions show projected increases in cat $4-5$ occurrence but decreases in overall tropical cyclone occurrence (Figs. 8 and 9). Among these are most of the North Atlantic basin and much of the northwest Pacific basin. The north Indian Ocean shows a significant projected increase in hurricane-force tropical cyclone frequency and cat $4-5$ occurrence days (Table 3 ).

Figure 10 shows the distribution of projected SST changes used in our downscaling experiments for the main tropical cyclone activity months for the Northern and Southern Hemisphere basins, taken as the JulyNovember and January-May seasons, respectively. The SST increases are relatively less in regions with strong decreases in tropical cyclone and cat 4-5 occurrence (e.g., southwest Pacific basin) and are relatively greater in regions with strong increases, such as the northeast Pacific basin. This is illustrated quantitatively in the bottom panel of Fig. 10, which contains a scatterplot of relative SST change versus percent change in hurricane occurrence at each grid point in the domain $30^{\circ} \mathrm{N}-30^{\circ} \mathrm{S}$.
For this analysis, relative SST is defined as the local SST change at a grid point for the appropriate season (JulyNovember or January-May) compared to the average SST change over $30^{\circ} \mathrm{N}-30^{\circ} \mathrm{S}$ for that same season. The relation of relative SST to tropical cyclone potential intensity has been previously illustrated in Vecchi and Soden (2007). The grid point by grid point correlation of hurricane occurrence changes in the hurricane model versus relative SST changes for the season is 0.63 . For tropical cyclone occurrence (not shown) the correlation is 0.45 . Thus relative SST changes appear to be important in statistically describing the spatial patterns of tropical cyclone and hurricane occurrence changes in the GFDL hurricane model downscaling.

Aggregate measures of tropical cyclone activity such as accumulated cyclone energy (ACE) or the power dissipation index (PDI) incorporate frequency, intensity, and duration characteristics. These are formed by summing the maximum surface wind intensity of a storm-raised to the second power for ACE and to the third power for PDI-at each 6-hourly period, then summing over all storms occurring during the 
a) July-Nov.

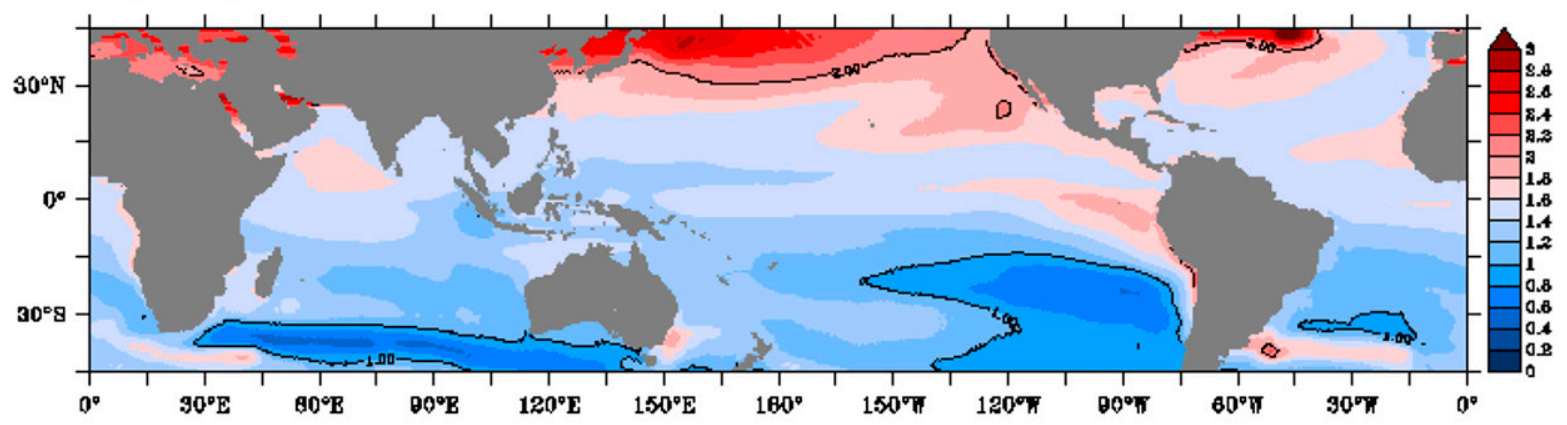

b) Jan.-May

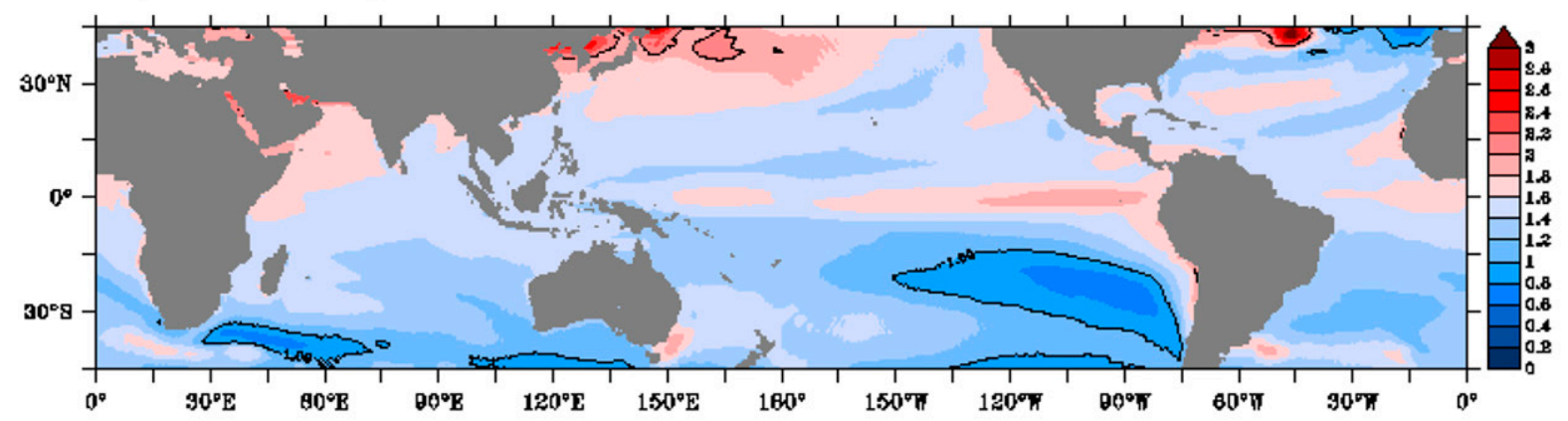

C) Cat $1-5$ storm frequency change vs. Relative SST change

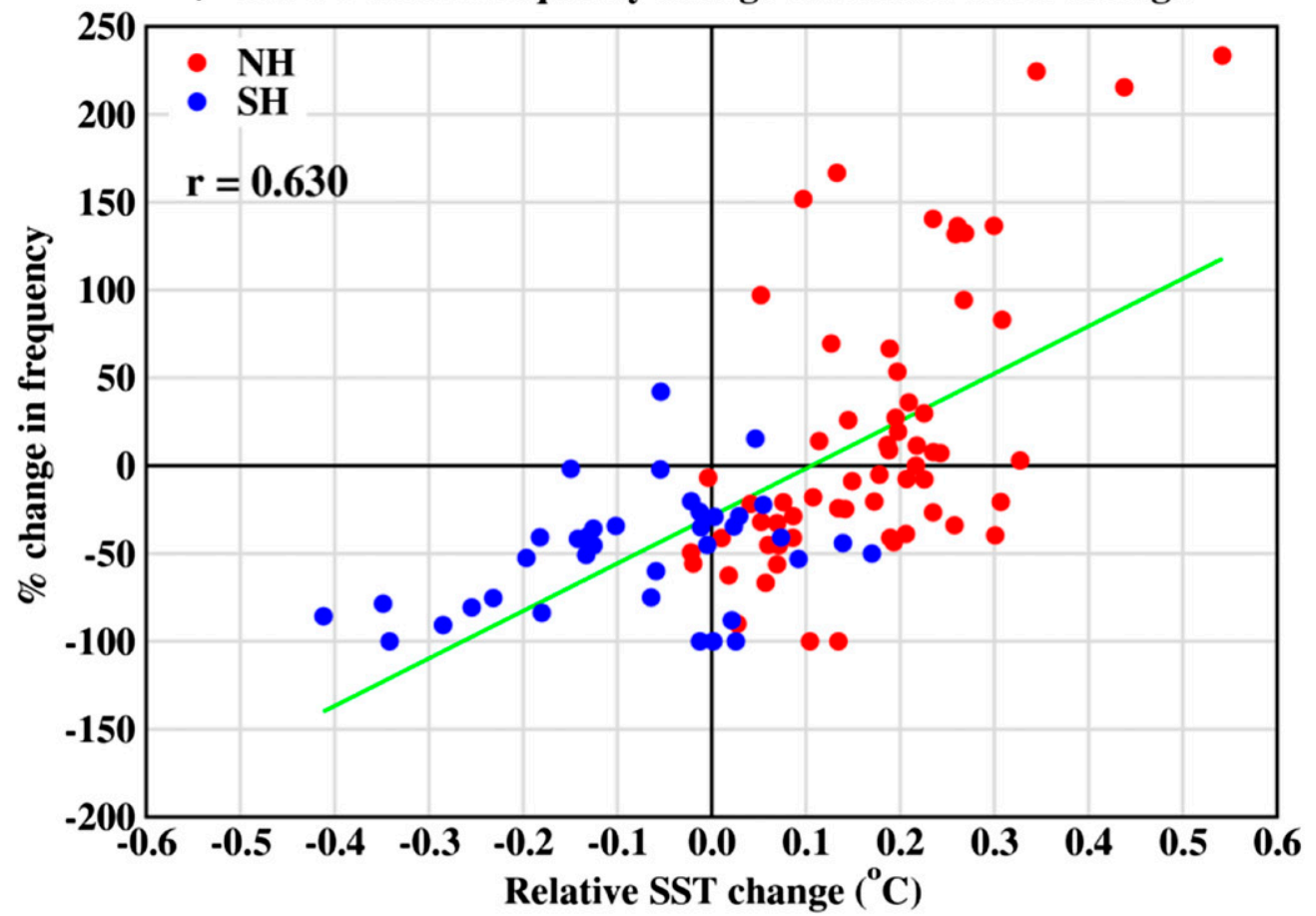

FIG. 10. SST difference (CMIP5/RCP4.5 late twenty-first century minus present day) used in the tropical cyclone dynamical downscaling experiments for the (a) July-November or (b) January-May seasons (units: ${ }^{\circ} \mathrm{C}$ ). (c) Scatterplot of percent change in hurricane (cat 1-5) occurrence frequency vs relative SST difference for each $10^{\circ} \times 10^{\circ}$ grid box $\left(30^{\circ} \mathrm{N}-30^{\circ} \mathrm{S}\right)$ that had nonzero hurricane occurrence in both control and warm climate simulations. Relative SST differences are from (a) for all Northern Hemisphere basin points (red) and from (b) for all Southern Hemisphere basin points (blue) shown in (c), and are relative to the average SST change over $30^{\circ} \mathrm{N}-30^{\circ} \mathrm{S}$. 


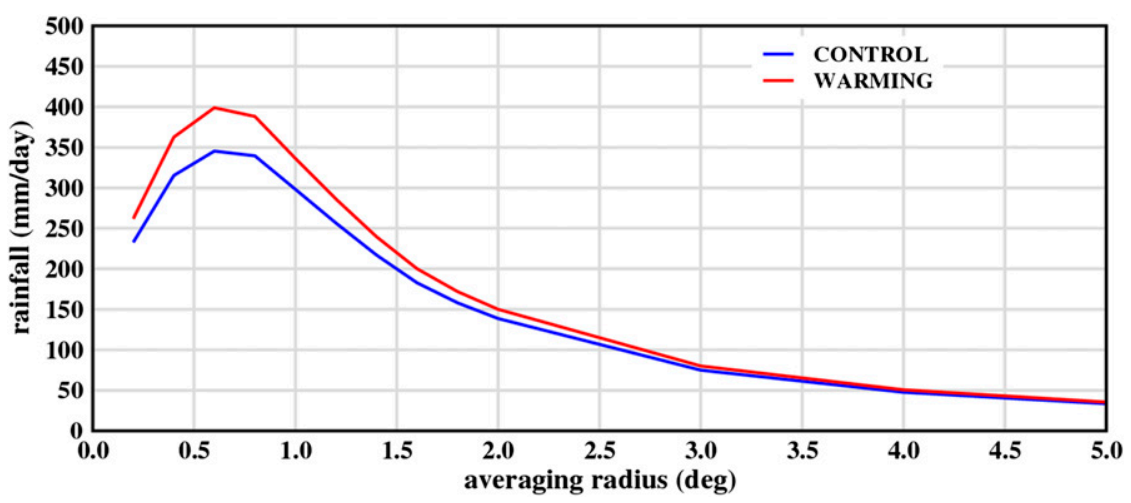

FIG. 11. Profiles of tropical cyclone precipitation rates $\left(\mathrm{mm} \mathrm{day}^{-1}\right)$, for the $10 \%$ rainiest tropical cyclones $\left(30^{\circ} \mathrm{N}-30^{\circ} \mathrm{S}\right)$ as in Fig. 4, but for the control runs (present day; blue curve) or the warming runs (late-twenty-first-century RCP4.5 projection; red curve).

period/region of consideration. For our earlier downscaling studies with the GFDL hurricane model (e.g., Bender et al. 2010; Knutson et al. 2013), we did not assess the ACE or PDI changes for the high-resolution runs because the experiments were limited to 5 days duration. Since we have now expanded the runs to up to 15 days in length per storm we can more reasonably analyze these metrics. Both ACE and PDI decrease globally, by $-13 \%$ and $-10 \%$, respectively (Table 3 ). This reflects the partially offsetting influences of decreased overall storm frequency and increase in average storm intensity, with the reduction in frequency apparently being the dominating influence. At the basin scale, four of the six major basins have a simulated decrease while two (the northeast Pacific and north Indian basins) have a projected increase.

\section{d. Storm-related precipitation rate changes}

Figure 11 shows the changes in precipitation in simulated tropical cyclones as a function of radius, considering the $10 \%$ rainiest storms globally in each set of experiments. A clear increase is seen in the warm climate storms. Table 3 presents some summary statistics for tropical cyclone rain rates, averaged within $100 \mathrm{~km}$ of the storm center, considering tropical cyclones of various intensity classes and including all tropical cyclones-not just the $10 \%$ rainiest storms. Globally, this metric increases by $14 \%$ for tropical cyclones of at least tropical storm intensity and $13 \%$ for hurricanes. Comparable statistics for individual basins are also shown in Table 3. Considering all tropical cyclones, the precipitation rate increases in all basins except for the southwest Pacific basin, which shows a slight decrease $(-1.2 \%)$. Notably, this basin is also the single basin that has a decrease in average storm intensity $(-5.6 \%)$ and the largest percentage decreases in tropical cyclone, hurricane, and intense hurricane occurrence (Table 3).
Figure 12 shows the percent change in precipitation rate as a function of averaging radius (i.e., precipitation averaged over a disk of the given radius) for the various basins, considering all tropical cyclones. The dotted line in each panel gives an indication of the change in large-scale environmental water vapor in the basin, here approximated as $7 \%$ times the average SST change in the basin, based on the approximate rate of increase of saturation vapor pressure with temperature at surface temperatures characteristic of the lower troposphere (e.g., Held and Soden 2006). The enhanced percentage increase in precipitation rate near the storm center, which was prominently seen for our Atlantic tropical cyclone downscaling experiments in Knutson et al. (2013), is not seen in all of the individual basins in this study, nor was it evident in future projected tropical cyclone precipitation rates for landfalling storms over the eastern United States (Wright et al. 2015). The percent change in precipitation rate is typically similar to the water vapor scaling ( $7 \%$ times the SST change). Notable exceptions include the northeast Pacific and near the storm center (within $150 \mathrm{~km}$ ) in the northwest Pacific, where the precipitation rate increase exceeds the water vapor scaling, and the southwest Pacific, where the precipitation rate increase is systematically less than the water vapor scaling. These two basins are where the SST increases are largest and smallest, respectively, and where the intensity increase is greatest or decrease is greatest, respectively. The results suggest that in addition to the background water vapor content, the precipitation rate increase is enhanced by dynamical (convergence) increases, particularly in regions with large relative SST changes, and the precipitation rate can decrease in regions where the intensity change is negative and the relative SST change is negative. The relation of precipitation rate changes to relative SST 


\section{a) Global}

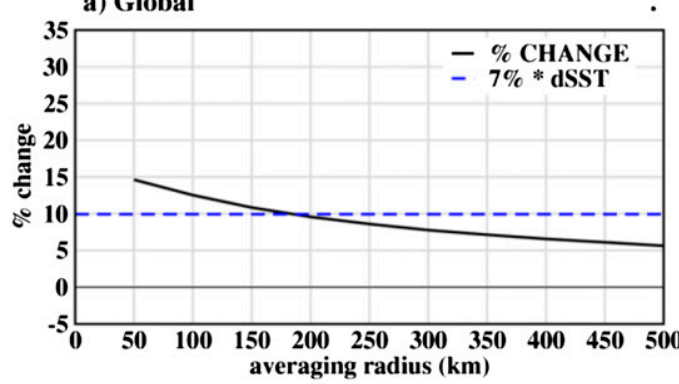

b) North Atlantic
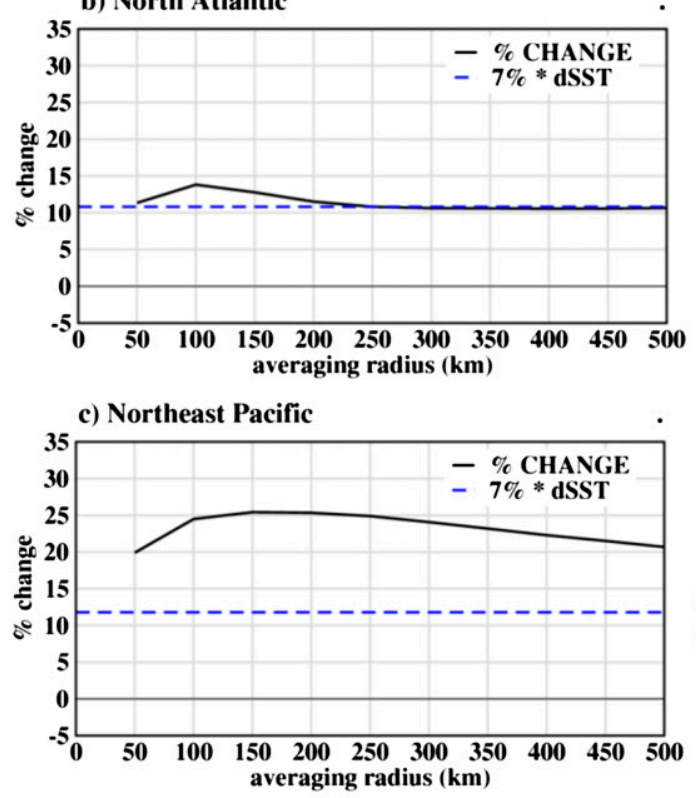

d) Northwest Pacific

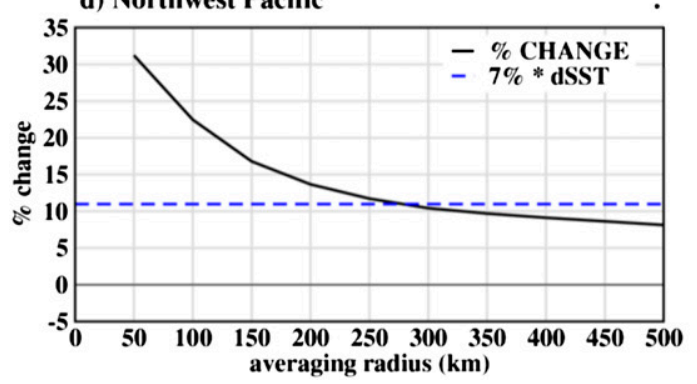

changes in the various basins will be examined further later in this report.

\section{e. Storm size changes}

In addition to intensity and track, storm size also plays an important role in modulating tropical cyclone damage (Zhai and Jiang 2014). Changes in size due to the warming scenario simulated here are shown in Fig. 5. Globally, median storm size stays nearly constant $(+1 \%)$; the change in mean of the log-transformed data is not statistically significant at the $5 \%$ level based on a e) North Indian Ocean
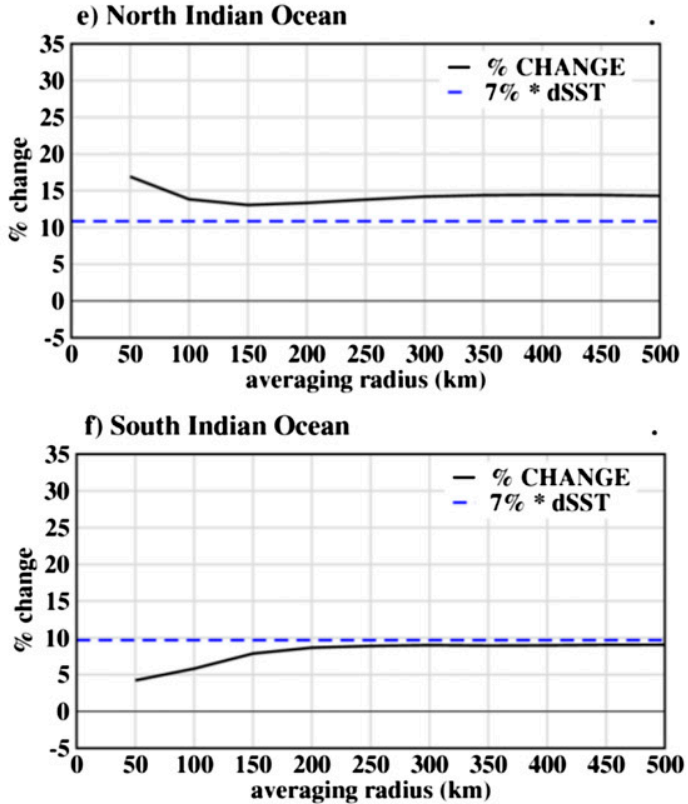

g) Southwest Pacific

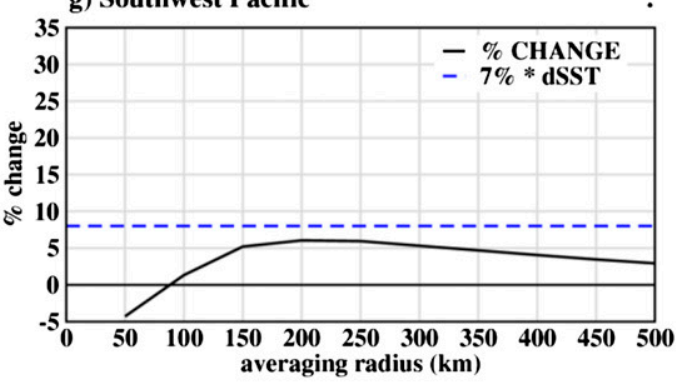

FIG. 12. Percent change (warm climate minus control) in tropical cyclone precipitation as a function of averaging radius from the storm center, for all tropical cyclones in each basin. The dotted line, computed as the SST change over the basin multiplied by $7 \%{ }^{\circ} \mathrm{C}^{-1}$, approximates the increase in atmospheric water vapor content in the basin associated with the SST warming, assuming negligible change in relative humidity.

Welch's two-sample $t$ test. Although the change in median size is negligible globally, this is not the case when looking across basins, where a decrease is found in the northwest Pacific $(-8 \%)$, with no statistically significant change in the north Indian basin and small increases in all other basins $(+7 \%$ to $+15 \%)$; the differences in sample size allow the northwest Pacific signal to balance those of the other basins. Notably, the two largest shifts are found in the northeast Pacific $(+15 \%)$ and North Atlantic basins $(+11 \%)$. The finer-grain details of changes in size will be explored in a future study. 


\section{Discussion and conclusions}

Using a two-step downscaling framework and the GFDL hurricane model, we have improved the intensity distributions of simulated tropical cyclones compared to the host HiRAM model. HiRAM C180 provides a fairly realistic tropical cyclone genesis distribution as the initial step in the downscaling but fails to capture tropical cyclones with winds of category 4 and 5 intensity, which we believe is important for late-twenty-first-century climate change projection studies. The inclusion of ocean coupling in our framework provides an important additional physical process that is not included in most other climate impacts studies. Moreover, this framework reproduces fairly well both the observed global distribution of storm intensity and outer storm size and their interbasin variability. The dynamical downscaling framework then provides a scenario-based assessment, including for very intense tropical cyclones, of changes in tropical cyclone frequency, precipitation, size, and intensity characteristics in response to the large-scale climate change (late twenty-first century) projection as simulated by a CMIP5 13-model ensemble using the RCP4.5 scenario.

Salient features of the late-twenty-first-century projected changes include a substantial reduction in global tropical cyclone frequency $(-16 \%)$, but an increase in the frequency of the most intense storms $(+24 \%$ for cat $4-5$ and $+59 \%$ for tropical cyclones with maximum winds exceeding $65 \mathrm{~m} \mathrm{~s}^{-1}$ ). The tropical cyclone frequency reduction is a relatively robust projection identified in previous studies (Knutson et al. 2010; Murakami et al. 2012a,b; Mallard et al. 2013; Zhao et al. 2013). The projected increased frequency of very intense tropical cyclones is consistent with the results from earlier downscaled studies using the GFDL hurricane model that were confined to only the Atlantic basin (Bender et al. 2010; Knutson et al. 2013) and with the global model study of Murakami et al. (2012b) .There is a larger projected fractional increase in the number of cat $4-5$ days $(+35 \%)$ compared to their frequency increase. Global averaged intensity of tropical cyclones and hurricanes increased by about $4 \%$. Global aggregate activity measures (ACE and PDI) show decreases of $-13 \%$ and $-10 \%$, indicating the dominating influence of the overall tropical cyclone frequency reduction over the influence of increased average intensity. Our results are quite different from the statistical-deterministic downscaling projections of Emanuel (2013) for CMIP5 models. Emanuel's projections include a large increase in global PDI and tropical cyclone frequency over the twenty-first century. Projected median storm size is found to remain nearly constant globally in our projections.
In terms of regional distribution, the increase in projected cat 4-5 occurrence is fairly widespread in the Northern Hemisphere basins (Fig. 9). Tropical cyclones in general (cat 0-5), while decreasing in occurrence in the majority of regions as well as the global average, still show some regions of increase, particularly in the central and eastern North Pacific including in the vicinity of Hawaii, which is qualitatively similar to climate change projection results reported in previous studies (Murakami et al. 2013). There is also decreased cat 4-5 occurrence projected in some areas, but these are more limited regions-notably the southwest Pacific and eastern Indian Ocean basins, and parts of the northwest Pacific basin. Interestingly, the region of the southwest Pacific near northeast Australia, which is one area of projected decrease in tropical cyclone activity, including cat 4-5 storms, is also a region where past data analysis indicates a downward trend in intense tropical cyclone landfalls over the past century (Callaghan and Power 2011). While results from the RCP4.5 forcing scenario cannot be straightforwardly compared with an historical forcing scenario, this finding may suggest the possibility of detecting a human influence on tropical cyclone activity (i.e., a decrease) in this region on the basis of a long (century scale) record of intense tropical cyclone landfalls in northeast Australia. Projected median storm size increases in most basins, but this is offset by a decrease in the northwest Pacific, resulting in a negligible increase globally $(+1 \%)$. Notable increases occur in the northeast Pacific $(+15 \%)$ and North Atlantic basins $(+11 \%)$ in these simulations.

The tropical cyclone precipitation results shown here, with a pronounced increase in the warmer climate, are consistent with earlier studies (e.g., Knutson et al. 2010, 2013; Villarini et al. 2014). We do not find strong evidence to support the enhanced rate nearer the storm center as found by Knutson et al. (2013) for the Atlantic basin. Additionally, our results (e.g., Table 3) suggest a link between average tropical cyclone precipitation rate change at the basin level and the simulated change in TC intensity. A physical mechanism suggested by the results (see also Wang et al. 2015) is that enhanced tropospheric water vapor in the warmer climate enhances moisture convergence and thus rainfall rates, but that in a basin where the average intensity of tropical cyclones decreases, the reduced tropical cyclone circulation intensity can offset the higher water vapor content and even produce a small decrease in tropical cyclone precipitation rates in that basin.

The projected tropical cyclone metric changes presented here vary by basin, with the interbasin spread being explained to a large extent by variation between the regions in the magnitude of SST change. This is illustrated and summarized in Fig. 13, which contains scatterplots of 
\# TS (Cat 0-5)
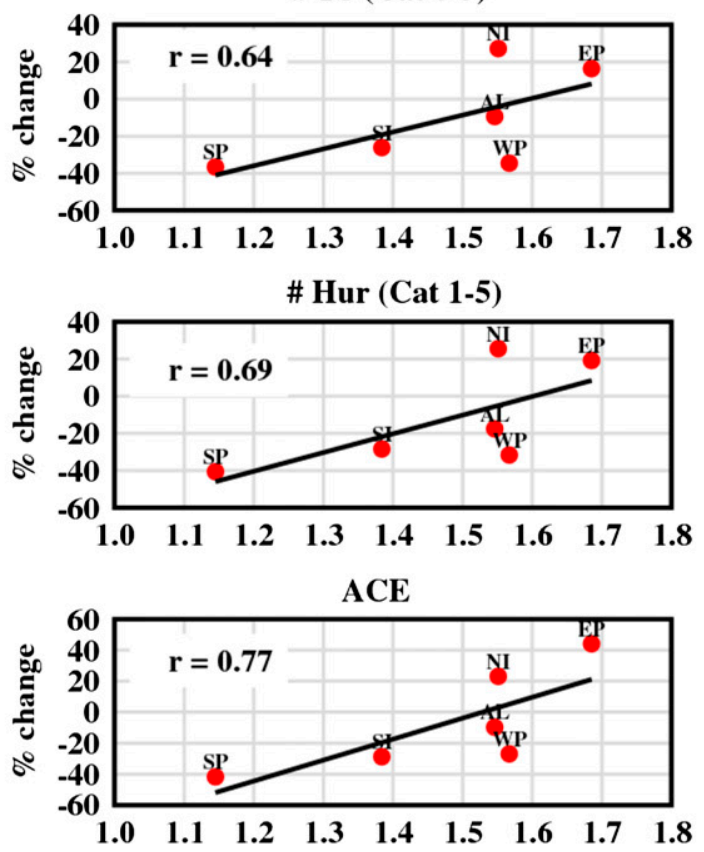

maxwnd TS
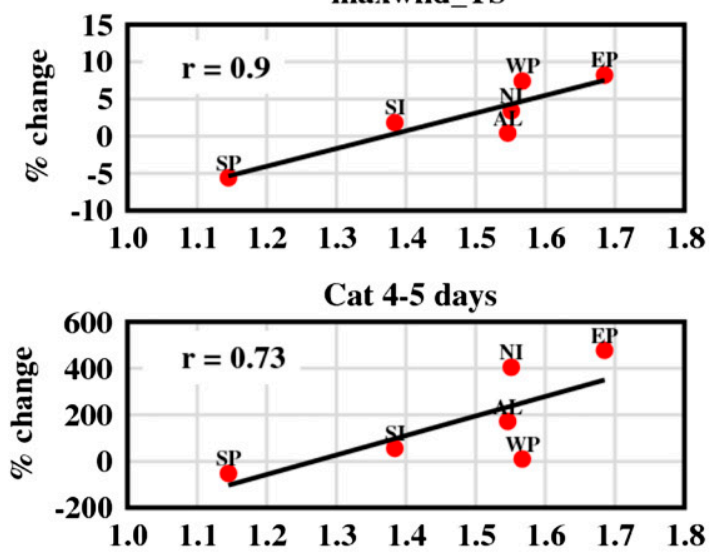

Rain rate (Cat 1-5)

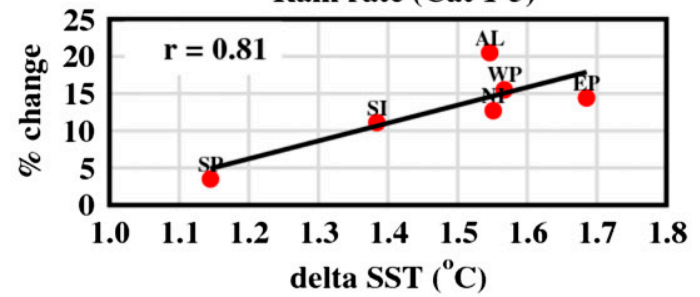

\# Hur (Cat 3-5)

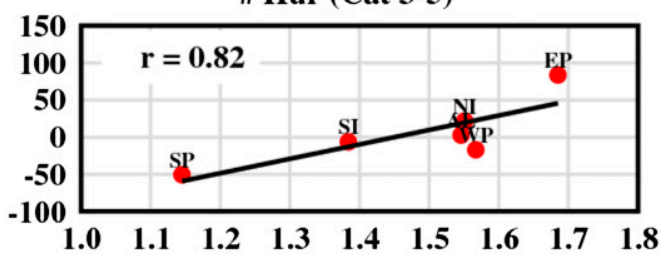

\# Hur (Cat 4-5)

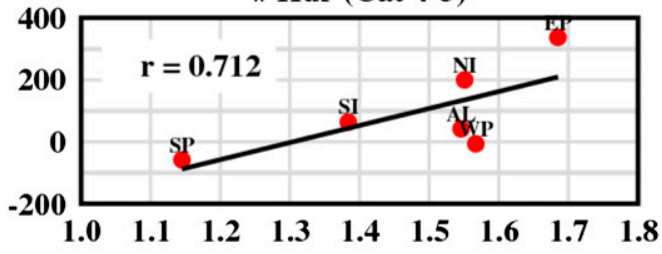

PDI

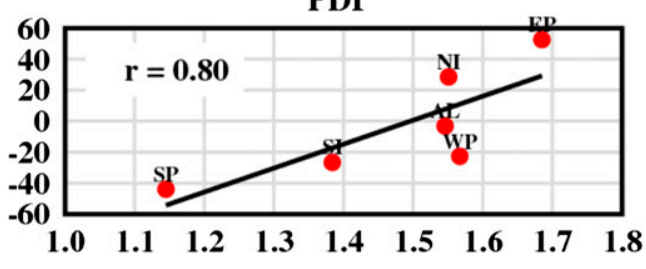

maxwnd_HUR

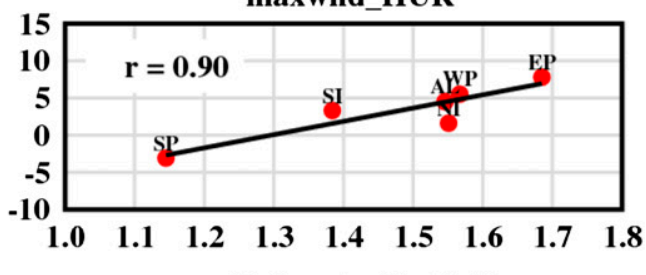

Rain rate (Cat 0-5)

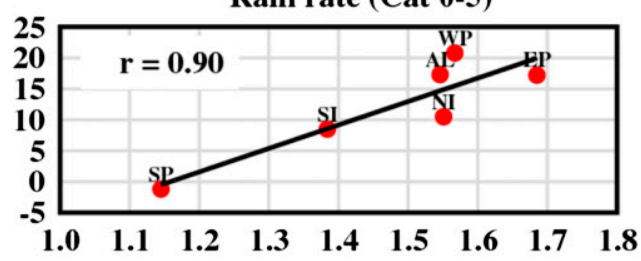

Rain rate (Cat 3-5)

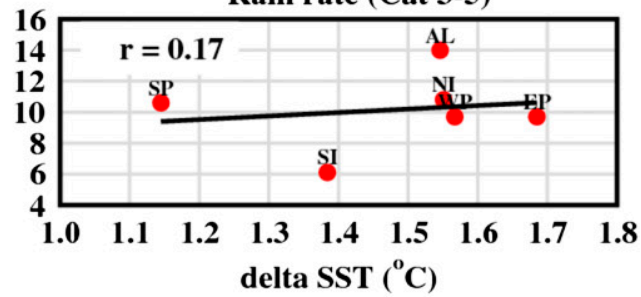

FIG. 13. Scatterplots and linear correlations $(r)$ of the percent change in various tropical cyclone metrics (warm climate vs control) plotted against the average change in SST (warm minus control, in ${ }^{\circ} \mathrm{C}$ ) for each basin. Metrics analyzed in each panel are identified in the text above each panel. Rainfall metrics are for all tropical cyclones for the categories stated. See main text or the caption of Table 3 for further details.

the percent change in a number of tropical cyclone metrics by basin versus the average SST increase in the basins. The size of SST increase in each basin (essentially the relative SST change) appears to be a reasonable statistical predictor of the interbasin variation of response in storm frequency for various category storms, of ACE and PDI, of maximum storm intensity, of cat 4-5 days, and of precipitation rates within $100 \mathrm{~km}$ of storm center-the latter 
at least for tropical cyclones collectively and hurricanes (cat 1-5). With the exception of the case for precipitation rate for cat 3-5 hurricanes, which has a negligible correlation, all of the other metrics have a substantial correlation with the basinwide SST changes, ranging from 0.64 to 0.9. This finding highlights the importance of reliable projections of the interbasin variations or patterns of future SST change from climate models, in addition to the overall tropical mean magnitude of the warming, for future tropical cyclone changes (see also Sugi et al. 2009). Future research will continue to address the issue of robustness of projections to the use of different downscaling frameworks such as Emanuel (2013). Nonetheless, our results suggest that narrowing uncertainties of the largescale climate change inputs to the downscaling frameworks (e.g., SST change patterns) is an important research task for reducing uncertainty in future tropical cyclone projections worldwide.

Acknowledgments. We thank Tim Marchok and an anonymous reviewer for helpful comments on our work. We acknowledge PCMDI and the modeling groups contributing to the CMIP3 and CMIP5 model archives for generously making their model output available to the community. This material is based in part upon work supported by the National Science Foundation under Grant AGS-1262099 (Gabriele Villarini and Gabriel A. Vecchi) and AGS-1331362 (Daniel R. Chavas). We acknowledge Hyeong-Seog Kim, sponsored by the Willis Research Network, for early developmental work on the global simulation framework. We acknowledge the assistance of Isaac Ginis and Richard Yablonsky of the University of Rhode Island on the hurricane model ocean coupling components.

\section{REFERENCES}

Bender, M. A., and I. Ginis, 2000: Real-case simulations of hurricaneocean interaction using a high-resolution coupled model: Effects on hurricane intensity. Mon. Wea. Rev., 128, 917-946, doi:10.1175/ 1520-0493(2000)128<0917:RCSOHO > 2.0.CO;2.

,,-- R. E. Tuleya, B. Thomas, and T. Marchok, 2007: The operational GFDL coupled hurricane-ocean prediction system and a summary of its performance. Mon. Wea. Rev., 135, 3965-3989, doi:10.1175/2007MWR2032.1.

— , T. R. Knutson, R. E. Tuleya, J. J. Sirutis, G. A. Vecchi, S. T. Garner, and I. M. Held, 2010: Modeled impact of anthropogenic warming of the frequency of intense Atlantic hurricanes. Science, 327, 454-458, doi:10.1126/science.1180568.

Bengtsson, L., K. I. Hodges, M. Esch, N. Keenlyside, L. Kornblueh, J.-J. Luo, and T. Yamagata, 2007: How may tropical cyclones change in a warmer climate? Tellus, 59A, 539-561, doi:10.1111/ j.1600-0870.2007.00251.x.

Callaghan, J., and S. Power, 2011: Variability and decline in the number of severe tropical cyclones making land-fall over eastern Australia since the late nineteenth century. Climate Dyn., 37, 647-662, doi:10.1007/s00382-010-0883-2.
Camargo, S., M. Ting, and Y. Kushnir, 2013: Influence of local and remote SST on North Atlantic tropical cyclone potential intensity. Climate Dyn., 40, 1515-1529, doi:10.1007/ s00382-012-1536-4.

Chavas, D. R., and K. A. Emanuel, 2010: A QuikSCAT climatology of tropical cyclone size. Geophys. Res. Lett., 37, L18816, doi:10.1029/2010GL044558.

—, and J. Vigh, 2014: QSCAT-R: The QuikSCAT tropical cyclone radial structure dataset. NCAR Tech. Note TN$513+$ STR, 27 pp.

_, N. Lin, and K. A. Emanuel, 2015: A model for the complete radial structure of the tropical cyclone wind field. Part I: Comparison with observed structure. J. Atmos. Sci., doi:10.1175/ JAS-D-15-0014.1, in press.

Christensen, J. H., and Coauthors, 2013: Climate phenomena and their relevance for future regional climate change. Climate Change 2013: The Physical Science Basis, T. F. Stocker et al., Eds., Cambridge University Press, 1217-1308.

Dunstone, N. J., D. M. Smith, B. B. B. Booth, L. Hermanson, and R. Eade, 2013: Anthropogenic aerosol forcing on Atlantic tropical storms. Nat. Geosci., 6, 534-539, doi:10.1038/ngeo1854.

Emanuel, K. A., 2004: Tropical cyclone energetics and structure. Atmospheric Turbulence and Mesoscale Meteorology, Cambridge University Press, 165-191.

, 2013: Downscaling CMIP5 climate models shows increased tropical cyclone activity over the 21st century. Proc. Natl. Acad. Sci. USA, 110, 12219-12224, doi:10.1073/pnas.1301293110.

, R. Sundararajan, and J. Williams, 2008: Hurricanes and global warming-Results from downscaling IPCC AR4 simulations. Bull. Amer. Meteor. Soc., 89, 347-367, doi:10.1175/ BAMS-89-3-347.

Held, I. M., and B. J. Soden, 2006: Robust responses of the hydrological cycle to global warming. J. Climate, 19, 5686-5699, doi:10.1175/JCLI3990.1.

- and M. Zhao, 2011: The response of tropical cyclone statistics to an increase in $\mathrm{CO}_{2}$ with fixed sea surface temperatures. J. Climate, 24, 5353-5364, doi:10.1175/JCLI-D-11-00050.1.

Hill, K. A., and G. M. Lackmann, 2011: The impact of future climate change on TC intensity and structure: A downscaling approach. J. Climate, 24, 4644-4661, doi:10.1175/2011JCLI3761.1.

Huang, P., I.-I. Lin, C. Chou, and R.-H. Huang, 2015: Change in ocean subsurface environment to suppress tropical cyclone intensification under global warming. Nat. Commun., 6, 7188, doi: $10.1038 /$ ncomms 8188 .

Huffman, G. J., and Coauthors, 2007: The TRMM Multisatellite Precipitation Analysis (TMPA): Quasi-global, multiyear, combined-sensor precipitation estimates at fine scales. J. Hydrometeor., 8, 38-55, doi:10.1175/JHM560.1.

IPCC, 2013: Climate Change 2013: The Physical Science Basis. T. F. Stocker et al., Eds., Cambridge University Press, 1535 pp.

Kim, H.-S., G. A. Vecchi, T. R. Knutson, W. G. Anderson, T. L. Delworth, A. Rosati, F. Zeng, and M. Zhao, 2014: Tropical cyclone simulation and response to $\mathrm{CO}_{2}$ doubling in the GFDL CM2.5 high-resolution coupled climate model. J. Climate, 27, 8034-8054, doi:10.1175/JCLI-D-13-00475.1.

Knutson, T. R., and S. Manabe, 1995: Time-mean response over the tropical Pacific to increased $\mathrm{CO}_{2}$ in a coupled oceanatmosphere model. J. Climate, 8, 2181-2199, doi:10.1175/ 1520-0442(1995)008<2181:TMROTT>2.0.CO;2.

, R. E. Tuleya, W. Shen, and I. Ginis, 2001: Impact of $\mathrm{CO}_{2}-$ induced warming on hurricane intensities simulated in a hurricane model with ocean coupling. J. Climate, 14, 2458-2468, doi:10.1175/1520-0442(2001)014<2458:IOCIWO>2.0.CO;2. 
and Coauthors, 2010: Tropical cyclones and climate change. Nat. Geosci., 3, 157-163, doi:10.1038/ngeo779.

, and Coauthors, 2013: Dynamical downscaling projections of twenty-first-century Atlantic hurricane activity: CMIP3 and CMIP5 model-based scenario. J. Climate, 26, 6591-6617, doi:10.1175/JCLI-D-12-00539.1.

Lin, I.-I., and Coauthors, 2013: An ocean coupling potential intensity index for tropical cyclones. Geophys. Res. Lett., 40, 1878-1882, doi:10.1002/grl.50091.

Lin, N., and D. R. Chavas, 2012: On hurricane parametric wind and applications in storm surge modeling. J. Geophys. Res., 117, D09120, doi:10.1029/2011JD017126.

Mallard, M. S., G. M. Lackmann, A. Aiyyer, and K. Hill, 2013: Atlantic hurricanes and climate change. Part I: Experimental design and isolation of thermodynamic effects. J. Climate, 26, 4876-4893, doi:10.1175/JCLI-D-12-00182.1.

Meehl, G. A., C. Covey, T. Delworth, M. Latif, B. McAvaney, J. F. B. Mitchell, R. J. Stouffer, and K. E. Taylor, 2007: The WCRP CMIP3 multimodel dataset: A new era in climate change research. Bull. Amer. Meteor. Soc., 88, 1383-1394, doi:10.1175/BAMS-88-9-1383.

Murakami, H., R. Mizuta, and E. Shindo, 2012a: Future changes in tropical cyclone activity projected by multi-physics and multiSST ensemble experiments using the $60-\mathrm{km}$-mesh MRIAGCM. Climate Dyn., 39, 2569-2584, doi:10.1007/ s00382-011-1223-x

, and Coauthors, 2012b: Future changes in tropical cyclone activity projected by the new high-resolution MRI-AGCM. J. Climate, 25, 3237-3260, doi:10.1175/JCLI-D-11-00415.1.

_ B. Wang, T. Li, and A. Kitoh, 2013: Projected increase in tropical cyclones near Hawaii. Nat. Climate Change, 3, 749754, doi:10.1038/nclimate1890.

Oouchi, K., J. Yoshimura, H. Yoshimura, R. Mizuta, S. Kusunoki, and A. Noda, 2006: Tropical cyclone climatology in a globalwarming climate as simulated in a $20 \mathrm{~km}$-mesh global atmospheric model: Frequency and wind intensity analyses. J. Meteor. Soc. Japan, 84, 259-276, doi:10.2151/jmsj.84.259.

Pielke, R. A., J. Gratz, C. W. Landsea, D. Collins, M. A. Saunders, and R. Musulin, 2008: Normalized hurricane damages in the United States: 1900-2005. Nat. Hazards Rev., 9, 29-42, doi:10.1061/(ASCE)1527-6988(2008)9:1(29).

Song, J.-J., Y. Wang, and L. Wu, 2010: Trend discrepancies among three best track data sets of western North Pacific tropical cyclones. J. Geophys. Res., 115, D12128, doi:10.1029/ 2009JD013058.

Sugi, M., A. Noda, and N. Sato, 2002: Influence of global warming on tropical cyclone climatology: An experiment with the JMA global model. J. Meteor. Soc. Japan, 80, 249-272, doi:10.2151/ jmsj.80.249.

,- H. Murakami, and J. Yoshimura, 2009: A reduction of global tropical cyclone frequency due to global warming. SOLA, $\mathbf{5}$, 164-167, doi:10.2151/sola.2009-042.

,-- , and 2012: On the mechanism of tropical cyclone frequency changes due to global warming. J. Meteor. Soc. Japan, 90A, 397-408, doi:10.2151/jmsj.2012-A24.

Taylor, K. E., R. J. Stouffer, and G. A. Meehl, 2012: An overview of CMIP5 and the experiment design. Bull. Amer. Meteor. Soc., 93, 485-498, doi:10.1175/BAMS-D-11-00094.1.
Tory, K. J., S. S. Chand, J. L. McBride, H. Ye, and R. A. Dare, 2013: Projected changes in late-twenty-first-century tropical cyclone frequency in 13 coupled climate models from phase 5 of the Coupled Model Intercomparison Project. J. Climate, 26, 9946 9959, doi:10.1175/JCLI-D-13-00010.1.

Tuleya, R. E., M. DeMaria, and R. J. Kuligowski, 2007: Evaluation of GFDL and simple statistical model rainfall forecasts for U.S. landfalling tropical storms. Wea. Forecasting, 22, 56-70, doi:10.1175/WAF972.1.

Vecchi, G. A., and B. J. Soden, 2007: Effect of remote sea surface temperature change on tropical cyclone potential intensity. Nature, 450, 1066-1070, doi:10.1038/nature06423.

—, S. Fueglistaler, I. M. Held, T. R. Knutson, and M. Zhao, 2013: Impacts of atmospheric temperature trends on tropical cyclone activity. J. Climate, 26, 3877-3891, doi:10.1175/ JCLI-D-12-00503.1.

Villarini, G., and G. A. Vecchi, 2012: Twenty-first-century projections of North Atlantic tropical storms from CMIP5 models. Nat. Climate Change, 2, 604-607, doi:10.1038/ nclimate 1530 .

_ and - 2013: Projected increases in North Atlantic tropical cyclone intensity from CMIP5 models. J. Climate, 26, 32313240, doi:10.1175/JCLI-D-12-00441.1.

_ D. A. Lavers, E. Scoccimarro, M. Zhao, M. F. Wehner, G. A. Vecchi, T. R. Knutson, and K. A. Reed, 2014: Sensitivity of tropical cyclone rainfall to idealized global-scale forcings. J. Climate, 27, 4622-4641, doi:10.1175/JCLI-D-13-00780.1.

Wang, C.-C., B.-X. Lin, C.-T. Chen, and S.-H. Lo, 2015: Quantifying the effects of long-term climate change on tropical cyclone rainfall using a cloud-resolving model: Examples of two landfall typhoons in Taiwan. J. Climate, 28, 66-85, doi:10.1175/ JCLI-D-14-00044.1.

Wright, D. B., T. R. Knutson, and J. A. Smith, 2015: Regional climate model projections of rainfall from U.S. landfalling tropical cyclones. Climate Dyn., doi:10.1007/s00382-015-2544-y, in press.

Yablonsky, R., and I. Ginis, 2008: Improving the ocean initialization of coupled hurricane-ocean models using featurebased data assimilation. Mon. Wea. Rev., 136, 2592-2607, doi:10.1175/2007MWR2166.1

Yoshimura, J., and M. Sugi, 2005: Tropical cyclone climatology in a high-resolution AGCM-Impacts of SST warming and $\mathrm{CO}_{2}$ increase. SOLA, 1, 133-136, doi:10.2151/sola.2005-035.

Zhai, A. R., and J. H. Jiang, 2014: Dependence of US hurricane economic loss on maximum wind speed and storm size. Environ. Res. Lett., 9, 064019, doi:10.1088/1748-9326/9/6/064019.

Zhao, M., and I. M. Held, 2010: An analysis of the effect of global warming on the intensity of Atlantic hurricanes using a GCM with statistical refinement. J. Climate, 23, 6382-6393, doi:10.1175/ 2010JCLI3837.1.

,-- , S.-J. Lin, and G. A. Vecchi, 2009: Simulations of global hurricane climatology, interannual variability, and response to global warming using a 50-km resolution GCM. J. Climate, 22, 6653-6678, doi:10.1175/2009JCLI3049.1.

, and Coauthors, 2013: Robust direct effect of increasing atmospheric $\mathrm{CO}_{2}$ concentration on global tropical cyclone frequency: A multi-model inter-comparison. U.S. CLIVAR Variations, 11 (3), U.S. CLIVAR Office, Washington, D.C., $17-23$. 